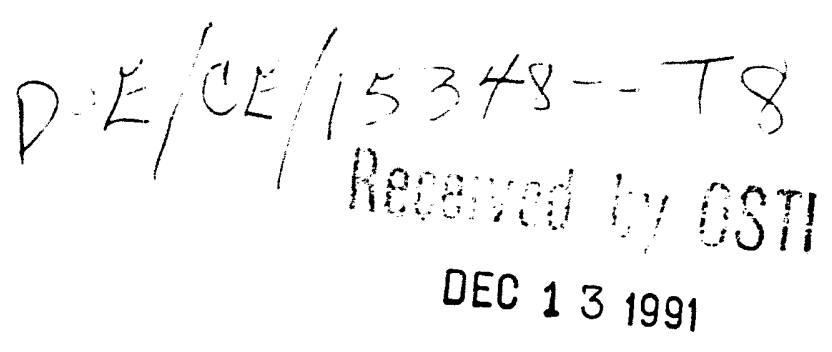

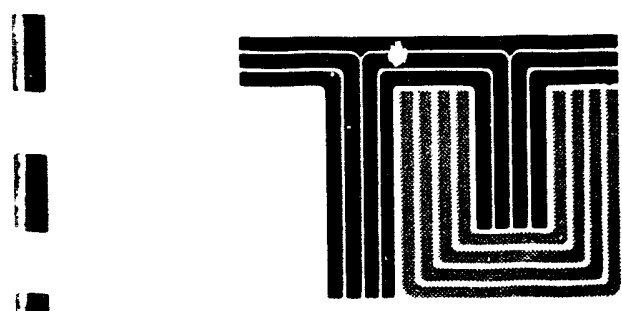

HERBERT EASTERLY AUXILIARY TRUCK HEATER

Final Technical Report

for

D.O.E. Contract \# DE-FG01-89CE15348

MCTR1291-01

Submitted to

Energy Related Inventions Program

December 9, 1991

Center for Manufacturing Research and

Technology Utilization

Cookeville, Tennessee 38505 


\title{
HERBERT EASTERLY AUXILIARY TRUCK HEATER
}

\author{
Final Technical Report \\ for \\ D.O.E. Contract \# DE-FG01-89CE15348
}

Submitted to

Energy Related Inventions Program

U.S. Department of Energy

1000 Independence Avenue, N.W.

Washington D.C. 20585

by

Center for Manufacturing Research and

Technology Utilization

Tennessee Technological University

Cookeville, Tennessee 38505

December 9, 1991

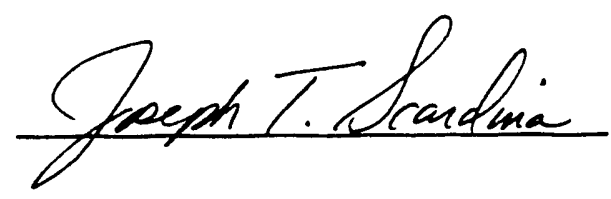

Joseph T. Scardina

Professor, Mechanical Engineering

Project Director 


\title{
EXECUTIVE SUMMARY
}

\author{
Herbert Easterly Auxiliary Truck Heater \\ D.O.E. Contract \# DE-FG01-89CE15348
}

The objective of this work was to continue the development of the Herbert Easterly heater apparatus (U.S. Patent 4,192,457) for vehicles, such as semi-trailer tractors in order to fully establish its technical feasibility and provide the basis for its commercialization. This heater is auxiliary to the vehicle's primary heating system. With the engine off it heats both the vehicle engine to a temperature at which it starts easily and the vehicle passenger compartment. Specifically, this heater is automatically ignitable, operates directly from the vehicle diesel fuel supply and preheats the vehicle engine fuel prior to combustion.

During the course of this work nine different versions of prototype heaters were designed, constructed and tested. All designs were based on the ideas and principles outlined in the Easterly patent. Each successive version incorporated design and fabrication improvements relative to the previous version. The final version, Prototype 9, utilized a multiple water jacket design to capture additional heat from the combustion gases prior to exhausting to the atmosphere. This final prototype exceeded the performance of a commercially available Webasto DBW-2010 using the same commercial burner as the one used in the Webasto unit. The time required to raise the heater fluid temperature by $120^{\circ} \mathrm{F}$ was $23 \%$ less ( 20 minutes compared to 26 minutes) for Prototype 9 compared to the commercially available unit.

In addition a prototype heat exchanger for preheating engine fuel was designed, fabricated and tested. This unit raised the temperature of diesel fuel $60^{\circ} \mathrm{F}$ in 9 minutes as the fluid temperature for the auxiliary heater increased from $122^{\circ} \mathrm{F}$ to $188^{\circ} \mathrm{F}$. A flow rate comparable to the maximum expected fuel consumption of a diesel engine was used. The incorporation of the fuel heat exchanger represents a capability not presently available with commercially available heaters.

It was also determined that the Prototype 9 auxiliary heater could operate at $85^{\circ}$ F for approximately 6 hours on a fully charged 12 volt marine battery rated to deliver 500 cold cranking amps. This operating time would be significantly reduced at sub-freezing temperatures. Accordingly, additional battery capacity would be needed for extended operation and some provision for heating the batteries with fluid from the auxiliary heater would be highly desirable. 
It was concluded that ? device based on Mr. Easterly's patent is technically feasible as is evidenced by the Prototype 9 results and the availability and use of commercial heaters which utilize similar principles to those described in Mr. Easterly's patent. Such devices should work well for preheating a cold engine and cab prior to starting the engine; but the usefulness of such auxiliary heaters for prolonged periods of time ( $6-8$ hours) for heating the cab is questionable due to high electric power consumption. Because of unusually mild weather conditions during the latter portion of this project and the excessively high cost of simulating sub-freezing conditions, all testing was carried out at temperatures that were much warmer than would be typical of situations when such heaters would be needed. It was calculated that the temperature increases measured for the heater would not be significantly different at lower temperatures, but electrical power consumption and heater combustion reliability would be expected to be significantly different. Thus there is a need for testing of such units under actual operating conditions.

This report was prepared as an account of work sponsored by an agency of the United Str'es Government. Neither the United States Government nor any agency thereof, nor any of their employees, makes any warranty, express or implied, or assumes any legal liability or responsibility for the accuracy, completeness, or usefulness of any information, apparatus, product, or process disclosed, or :epresents that its use would not infringe privately owned rights. Reference herein to any specific commercial product, process, or service by trade name, trademark, manufacturer, or otherwise does not necessarily constitute or imply its endorsement, recommendation, or favoring by the United States Government or any agency thereof. The views and opinions of authors expressed herein do not necessarily state or reflect those of the United States Government or any agency thereof. 


\section{Introduction}

On September 11, 1989, Tennessee Technological University was awarded a two year contract by the U.S. Department of Energy in response to a proposal entitled "Auxiliary Truck Engine Heater." The objective of this work was to continue the development of the Herbert Easterly heater apparatus (U.S. Patent 4,192,457) for vehicles, such as semi-trailer tractors in order to fully establish its technical feasibility and provide the basis for its commercialization. This heater is auxiliary to the vehicle's primary heating system. With the engine off it heats both the vehicle engine to a temperature at which it starts easily and the vehicle passenger compartment. Specifically, this heater is automatically ignitable, operates directly from the vehicle diesel fuel surply and preheats the vehicle engine fuel prior to combustion.

The tasks to be performed by Tennessee Technological University were:

Task 1. Prepare a detailed engineering design

Task 2. Order necessary parts and fabricate those that cannot be ordered

Task 3. Construct the prototype

Task 4. Perform testing under varying simulated environmental conditions

Task 5. Conduct feasibility analysis for technical validity and commercial viability

Task 6. Write a final report to communicate this work to the Department of Energy and the potential user community

Tasks one through five have been completed and the results are discussed in this report which constitutes task six.

\section{Prototype Design and Fabrication}

During the course of this work nine different versions of prototype heaters were designed, constructed and tested. All designs were based on the ideas and principles outlined in the Easterly patent. Each successive version incorporated design and fabrication improvements relative to the previous version.

During the first quarter of the project discussions were initiated by members of the Tennessee Tech project team with Mr. Herb Easierly. These discussions defined expected 
design and operating parameters for the auxiliary heater based on Mr. Easterly's patent concepts. The importance of rapid warming of a cold engine, the use of the same diesel fuel for the auxiliary heater as that used to power the truck engine and the ability to preheat the cab, the engine block and the fuel supplied to the engine were stressed by Mr. Easterly.

During the second quarter an evaluation test procedure using a 619 cubic inch, model 8630, 6-cylinder John Deere diesel engine was developed. Prototype 1 was also designed and fabricated during this period. Its geometry is shown in Figure 1. Based on preliminary testing, this geometry which was similar to that suggested by Mr. Easterly was found to be unsatisfactory because of its large size which added five gallons of coolant to the overall system. This prototype heat exchanger was able to transfer approximately $12,000 \mathrm{BTU} / \mathrm{hr}$ to the coolant.

During the third quarter Prototype 2 was designed and fabricated. Its geometry is shown in Figure 2. This design was considerably smaller than the previous unit and held less coolant while having nearly the same surface area for heat transfer. Prototype 2 was able to transfer approximately $15000 \mathrm{BTU} / \mathrm{hr}$ to the coolant.

During the fourth quarter Prototypes 3 and 4 were designed and fabricated. Their geometries are shown in Figures 3 and 4 respectively. Prototype 3 was essentially the same as Prototype 2 except that its water jacket thickness was reduced from 11/4 inches to $1 / 4$ inch and the shell side of the heat exchanger was reduced in size. These modifications were unable to increase the heat transfer characteristics which remained at approximately $15,000 \mathrm{BTU} / \mathrm{hr}$. Prototype 4 incorporated the basic water jacket geometry which would ultimately be used in the final prototype. This geometry is shown in Figure 5. All of the previous prototypes (i.e., 1, $2 \& 3$ ) were tested with a commercially available 50,000 BTU/hr burner obtained from a DESA International, model R50A portable space heater. Prototype 4 was tested with a lower output, 35,000 BTU/hr burner which was available for the DESA heater. Despite the $30 \%$ decrease in burner capacity, Prototype 4 still delivered $14,000 \mathrm{BTU} / \mathrm{hr}$ to the coolant representing a significant increase in performance.

During the fifth quarter three additional prototypes were developed and/or tested. Prototype 5, whose geometry is shown in Figure 6, was a slightly modified version of a gasoline fired, single-pass, counterflow heat exchanger made available by Mr. Easterly as the basis for a possible design. The unit was compact in size but was unable to heat the coolant the desired amount in a reasonable time. This unit used a much smaller output, gasoline fired burner. Prototype 6 utilized a bank of nine tubes to convey the hot, combustion gases past the heater coolant. The coolant passed over the outside of these tubes. This geometry is shown in Figure 7. This unit was tested with both the 35,000 


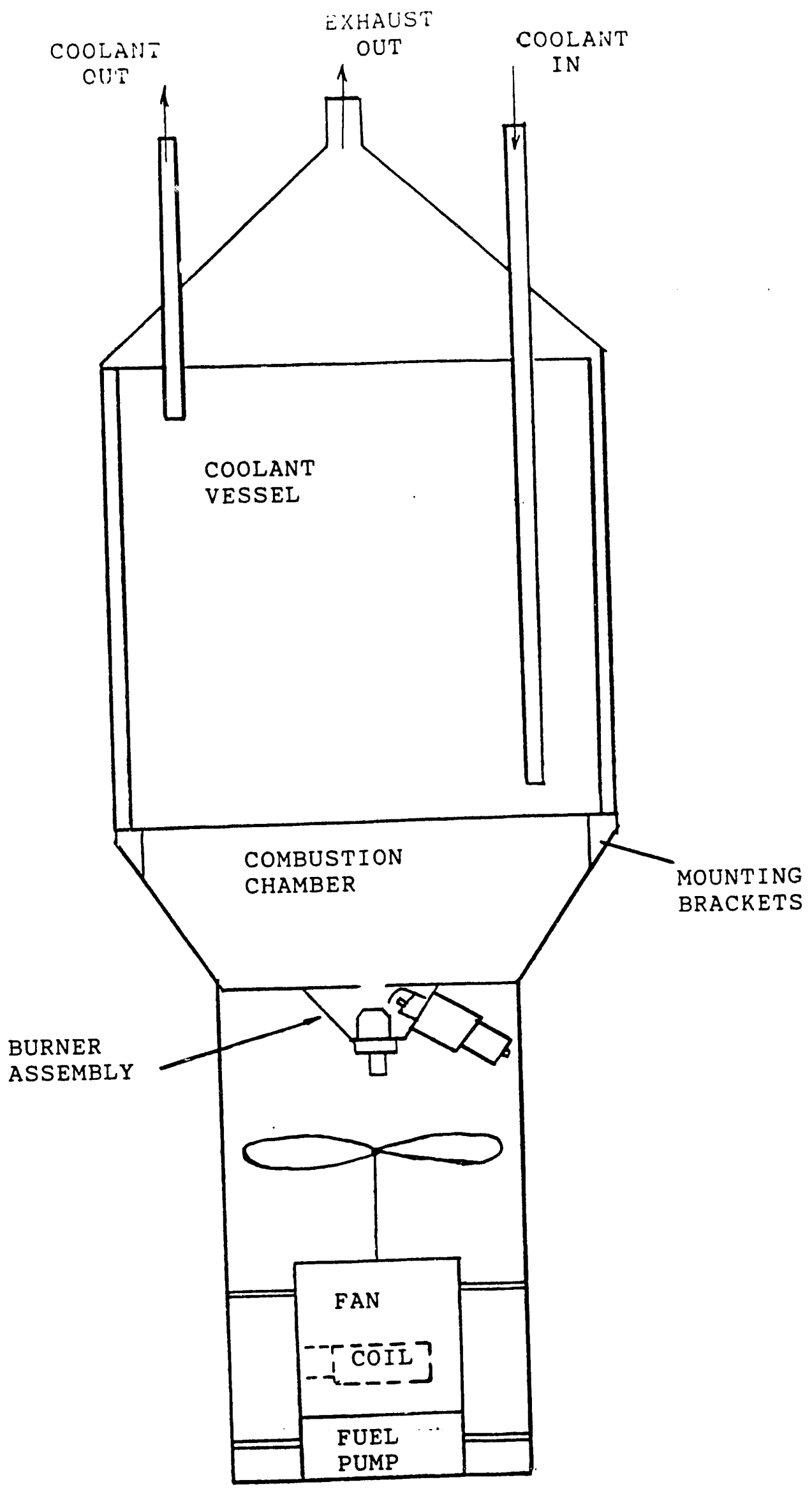

FIGURE 1: AUXILLIARY TRUCK HEATER (PROTOTYPE 1) 


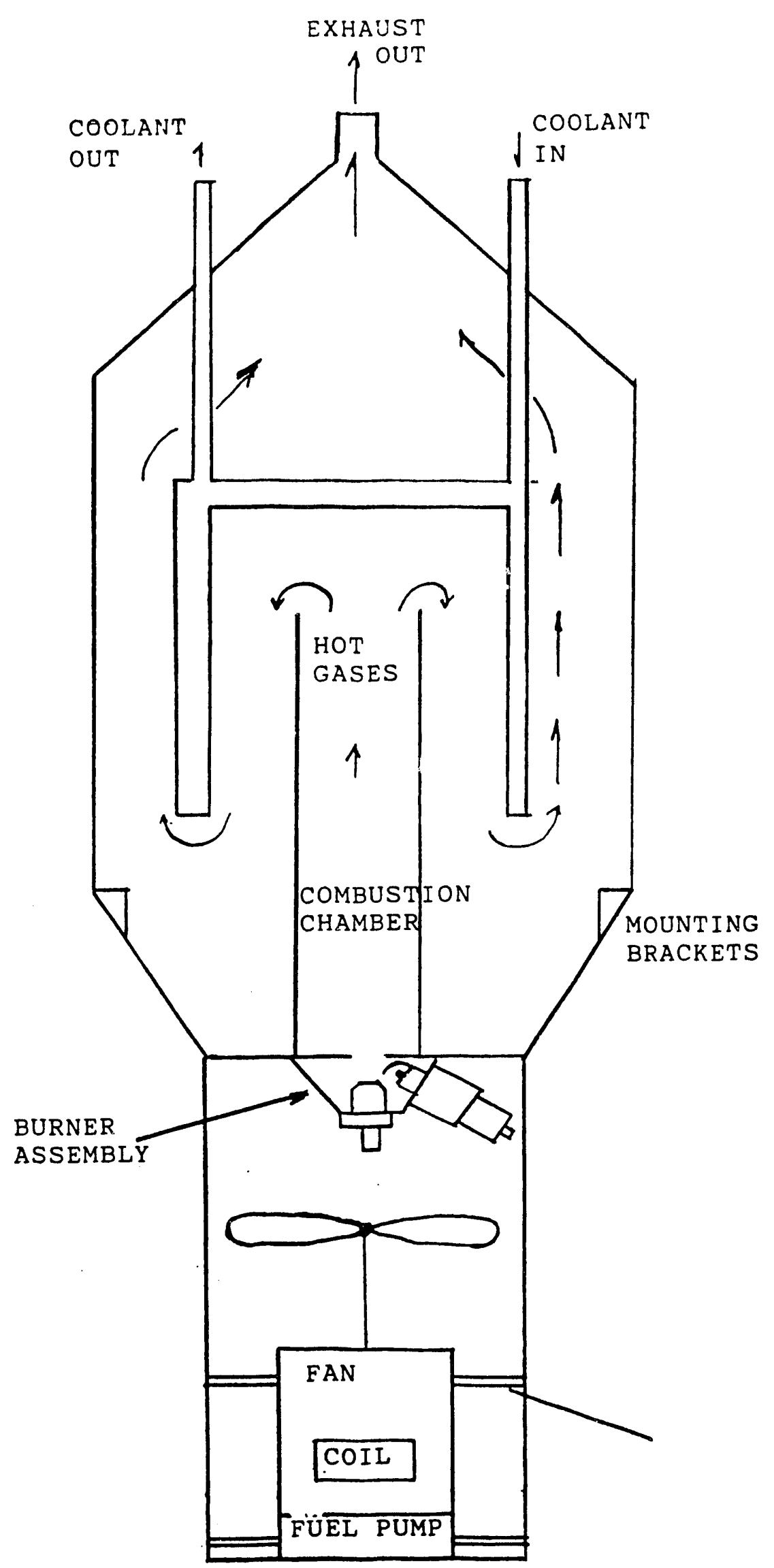

FIGURE 2: AUXILIARY TRUCK HEATER (PROTOTYPE 2) 


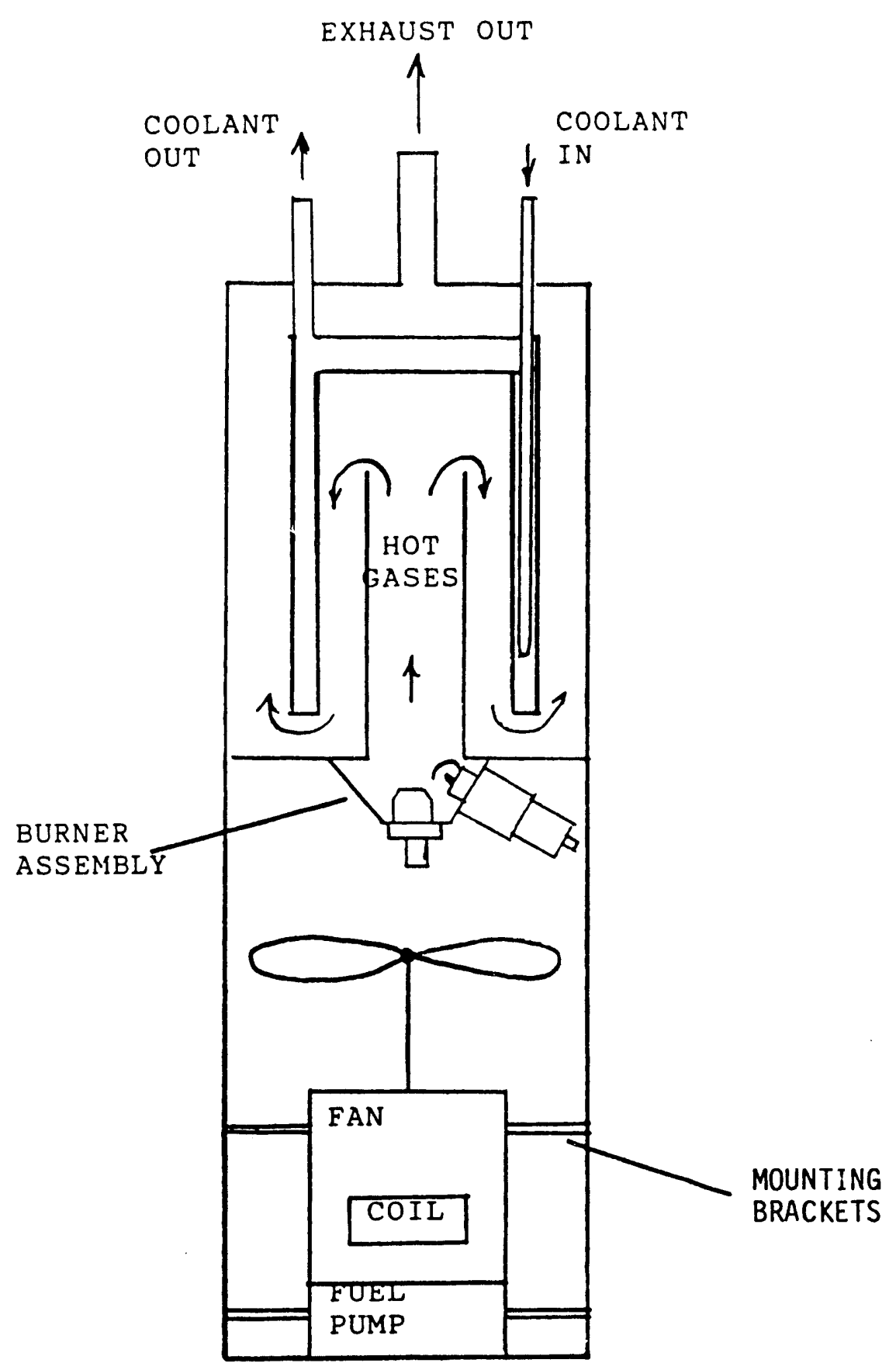

FIGURE 3: AUXILIARY TRUCK HEATER (PROTOTYPE 3) 


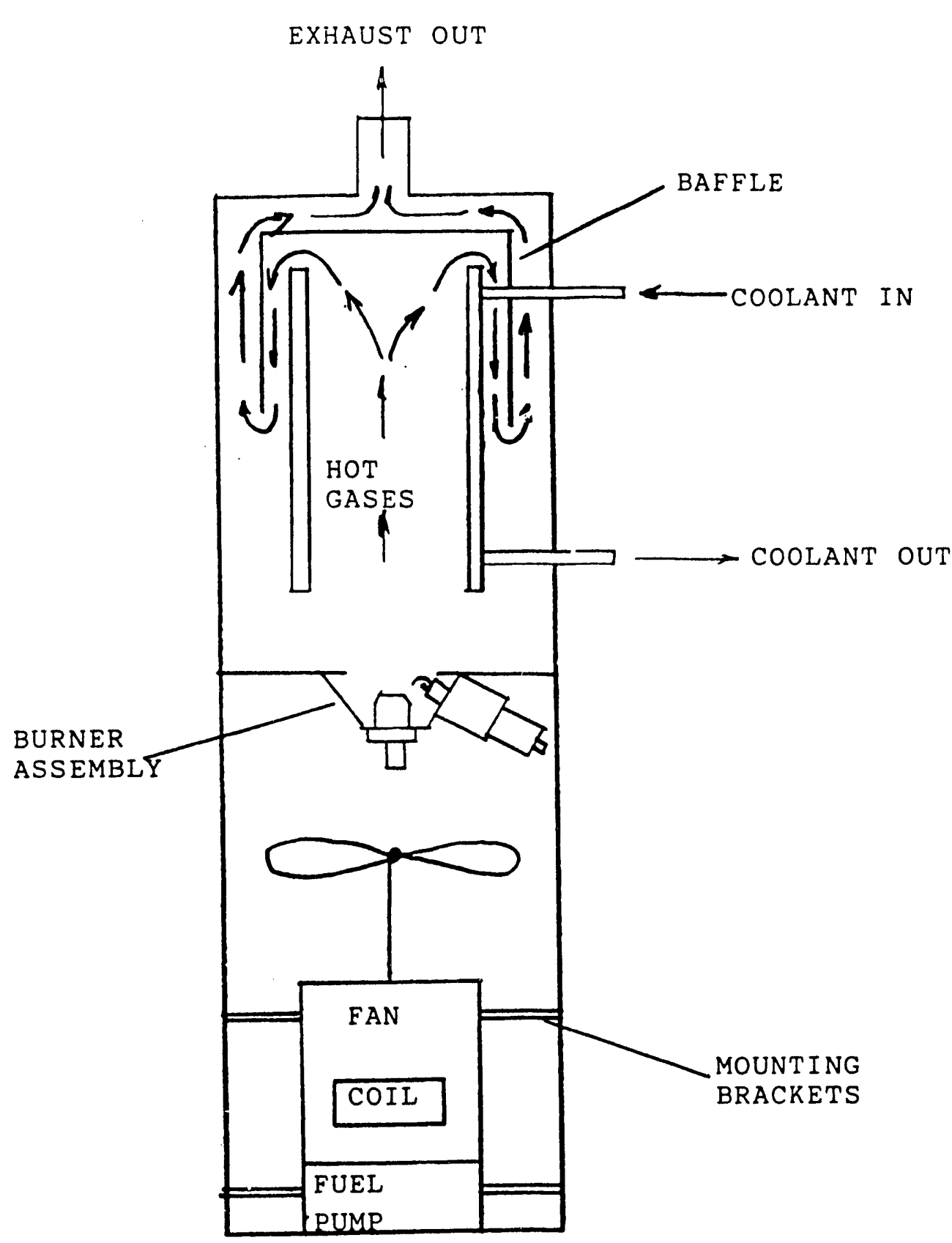

FIGURE 4: AUXILIARY TRUCK HEATER (PROTOTYPE 4) 


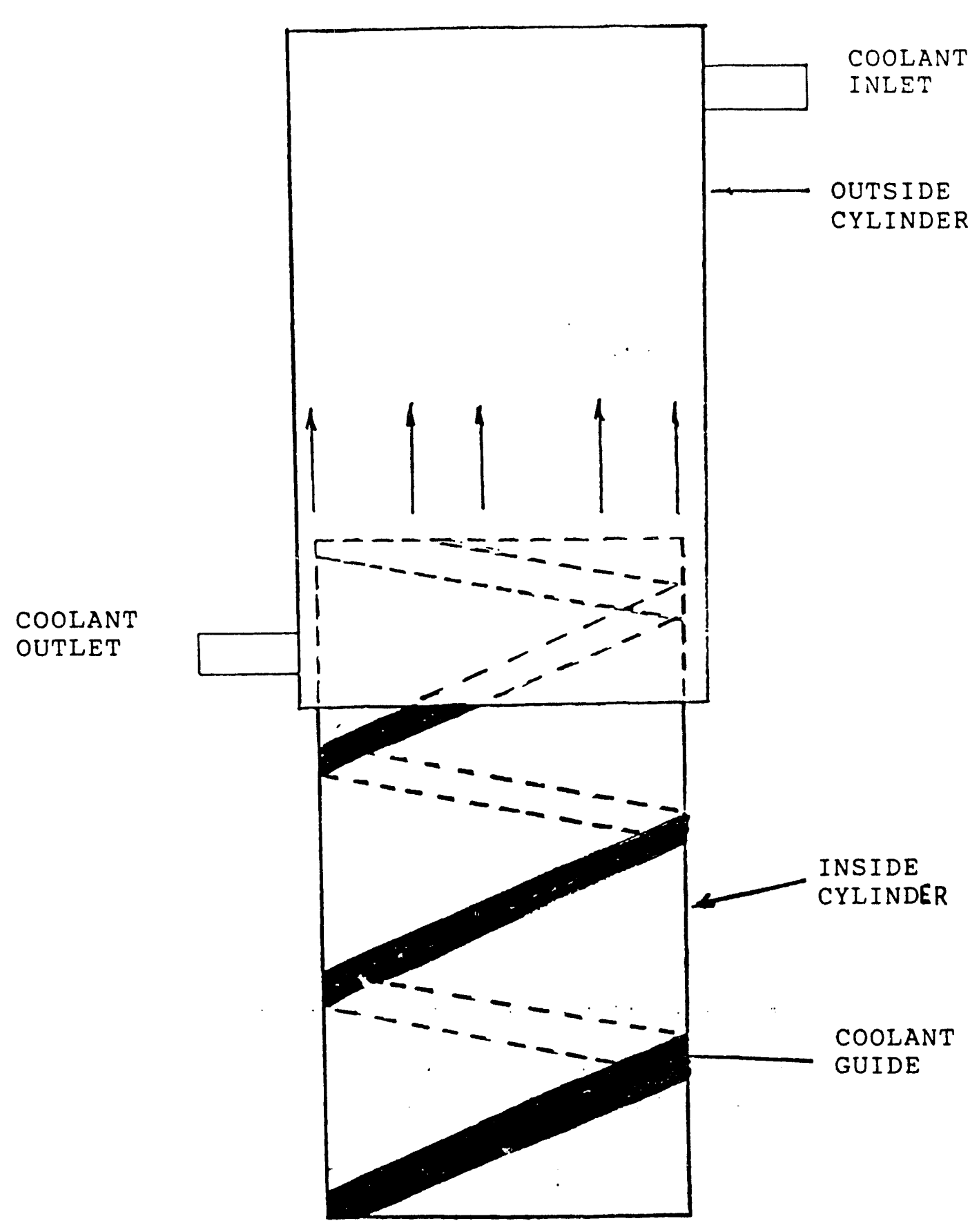

FIGURE 5: WATER JACKET USED IN FINAL DESIGN 


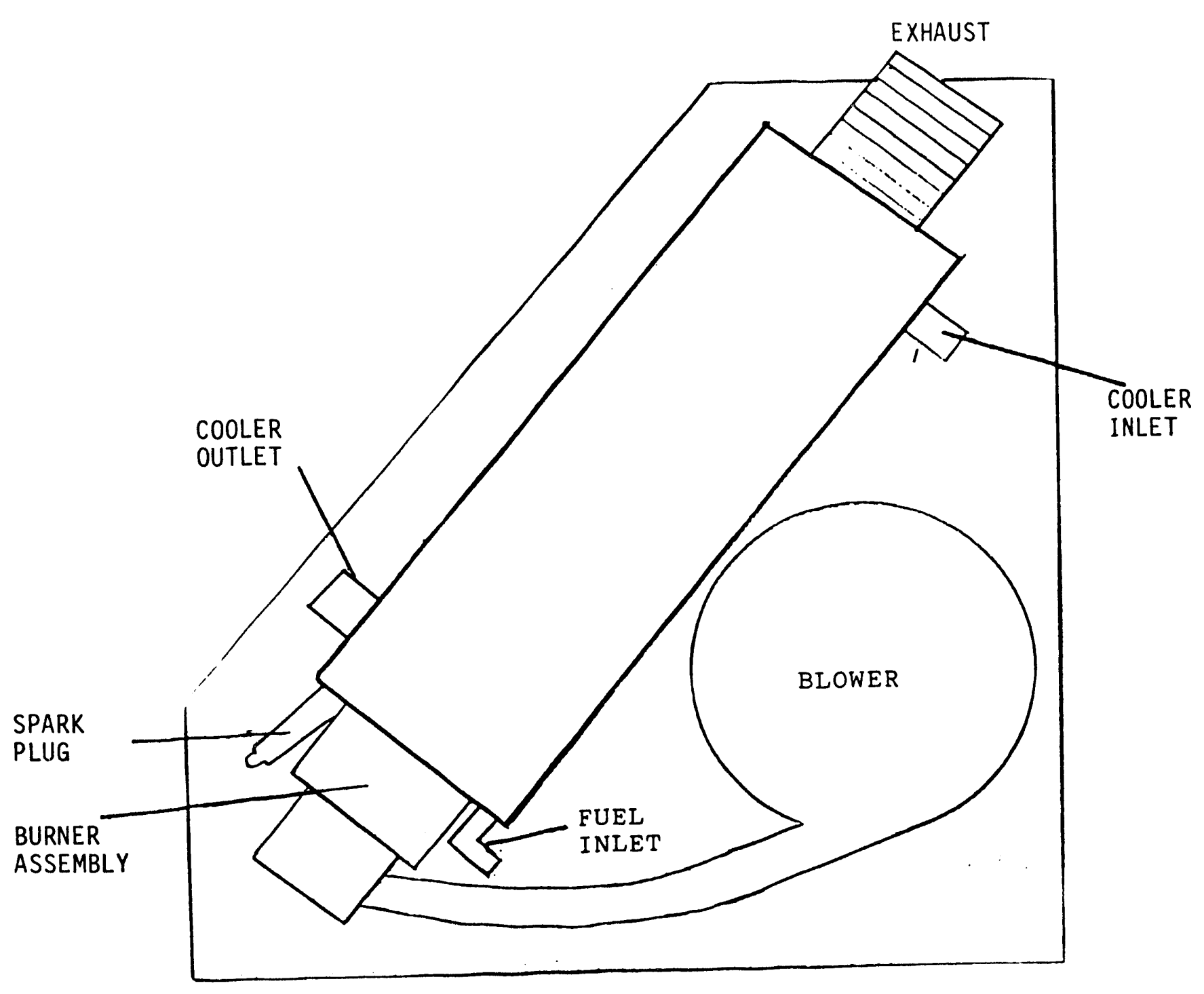

FIGURE 6: AUXILIARY ENGINE HEATER (PROTYPE 5) 


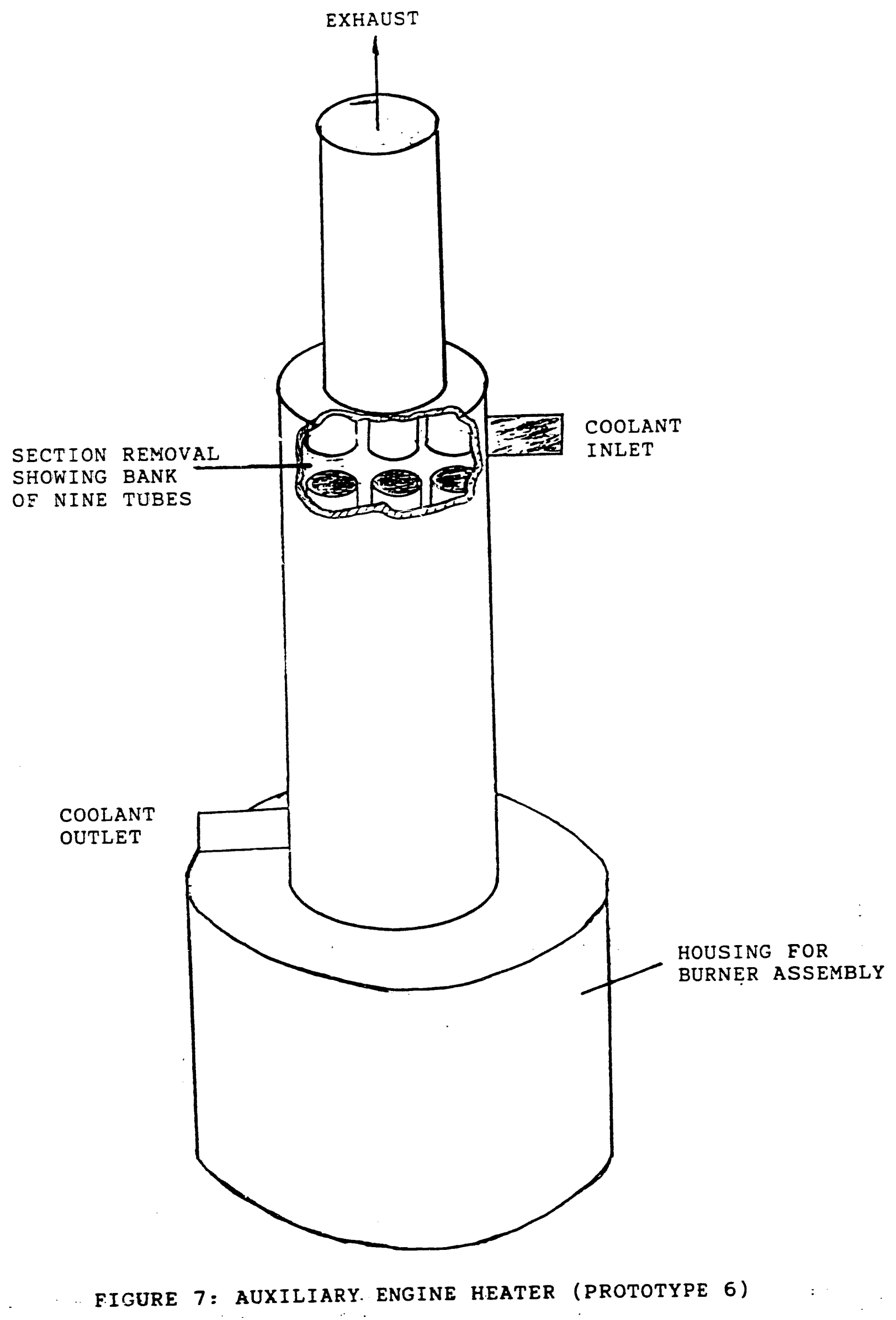


BTU/hr and the $50,000 \mathrm{BTU} / \mathrm{hr}$ burners. It performed reasonably well but was still inferior to Prototype 4. Thus it was decided to pursue a modified design based on the Prototype 4 geometry. These modifications resulted in the geometry shown in Figure 8 for Prototype 7.

Prototype 7 can be described as follows:

- The water side of the heat exchanger is comprised of two cylinders placed one inside the other with a $1 / 4$ inch gap for the flow of the coolant. The edges of both cylinders are welded togetter to close the system.

- The inlet to the water jacket is at one end of the cylinder and the outlet is at the other end. The outlet is at the burner end of the unit which makes this a counter flow heat exchanger. There is a guide in the water jacket which directs the coolant in a spiraled path around the cylinder. This spiraled path can be visualized with the aid of Figure 5 .

- An outside shell is placed around the water unit. This shell houses the exhaust of the combustion process. An exhaust port is located in the bottom of this outside shell.

- The heat from the combustion of diesel fuel passes through the center of the inside cylinder and back around the outside of the outside cylinder. This makes the shell side of the heat exchanger dual pass and therefore provides more surface area for heat transfer to occur.

Using either the $35,000 \mathrm{BTU} / \mathrm{hr}$ or the $50,000 \mathrm{BTU} / \mathrm{hr}$ burner, Prototype 7 performed considerably better than any of the previous prototypes. With the higher output burner it was capable of raising the coolant temperature by $114^{\circ} \mathrm{F}$ in one hour.

Thus, based on this initial screening of prototype geometries it was decided to adopt this basic geometry for further design refinements and testing. These refinements led to Prototype 8 and Prototype 9 which were tested extensively relative to a commercially auxiliary heater which was available commercially. These final two prototypes, the commercially available heater and the test results are discussed in detail in the next section of this report. 


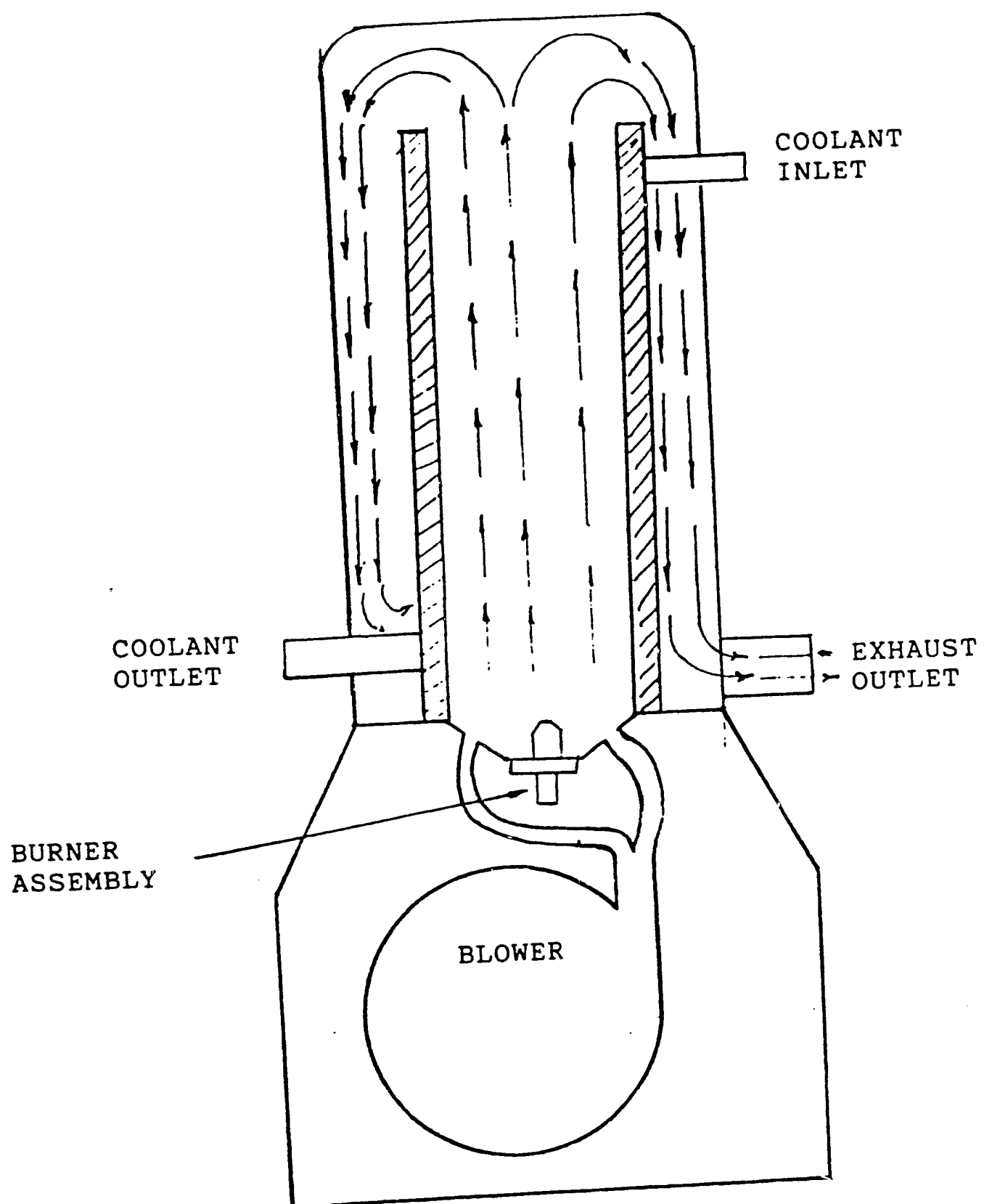

FIGURE 8: AUXILIARY ENGINE HEATER (PROTOTYPE 7) 


\section{Test Results for Prototypes Eight and Nine}

In testing Prototype 8 and Prototype 9, the procedure used was to monitor the change in auxiliary heater coolant temperature as a function as it circulated through the heater and the 619 cubic inch, model 8630 John Deere diesel engine. Initially the engine and the coolant were both at ambient temperature which ranged from $50^{\circ} \mathrm{F}$ to $70^{\circ} \mathrm{F}$ for various tests. As the coolant was heated by the auxiliary heater, both the coolant temperature as it left the engine and the engine block temperature near the coolant passages were monitored. In essence the engine served as a heat sink extracting heat from the coolant as it flowed through the block. Initially it had been planned to simulate subzero conditions by surrounding the engine with an insulated shroud and cooling it with liquid nitrogen sprayed on the exterior surfaces; however, this technique was prohibitively expensive due to the large amounts of liquid nitrogen required and could not be utilized. In addition an unusually mild winter in Tennessee prevented any testing at sub freezing temperatures. Instead it was decided to evaluate the heaters based on the ability to increase the coolant temperature by a significant amount (approximately $100^{\circ} \mathrm{F}$ above the ambient temperature) in a reasonable time (approximately 20 minutes) as it passed through the diesel engine block. Heat transfer calculations were carried out which showed that, within a reasonable approximation, this same temperature rise could be expected at subzero temperatures. Thus, a heater capable of raising coolant temperature from $70^{\circ} \mathrm{F}$ to $170^{\circ} \mathrm{F}$ should have sufficient capacity to raise the temperature to from $-40^{\circ} \mathrm{F}$ to $60^{\circ} \mathrm{F}$. These calculations assume that there are no significant convective effects due to wind chill effects.

Prior to testing these final two prototypes, it was decided to acquire another auxiliary heater which was commercially available. The model selected represented the highest capacity unit available which operated by burning diesel fuel. A Webasto Model DBW-2010 unit was purchased at the end of the fifth quarter of the project. The sixth and seventh quarters of the project were used for comparative testing of Prototype 8, Prototype 9 and the Webasto unit.

The geometry of the Webasto unit is shown in Figure 9. The figure shows the complete burner and heat exchanger unit. In order to obtain results which were obtained under the same test conditions, it was decided to use the Webasto burner on Prototype 8 and Prototype 9 as well as on the Webasto unit.

The geometry for Prototype 8 is shown in Figure 10. This prototype is nearly identical to Prototype 7 except for slight modifications to allow for attaching the Webasto burner. 


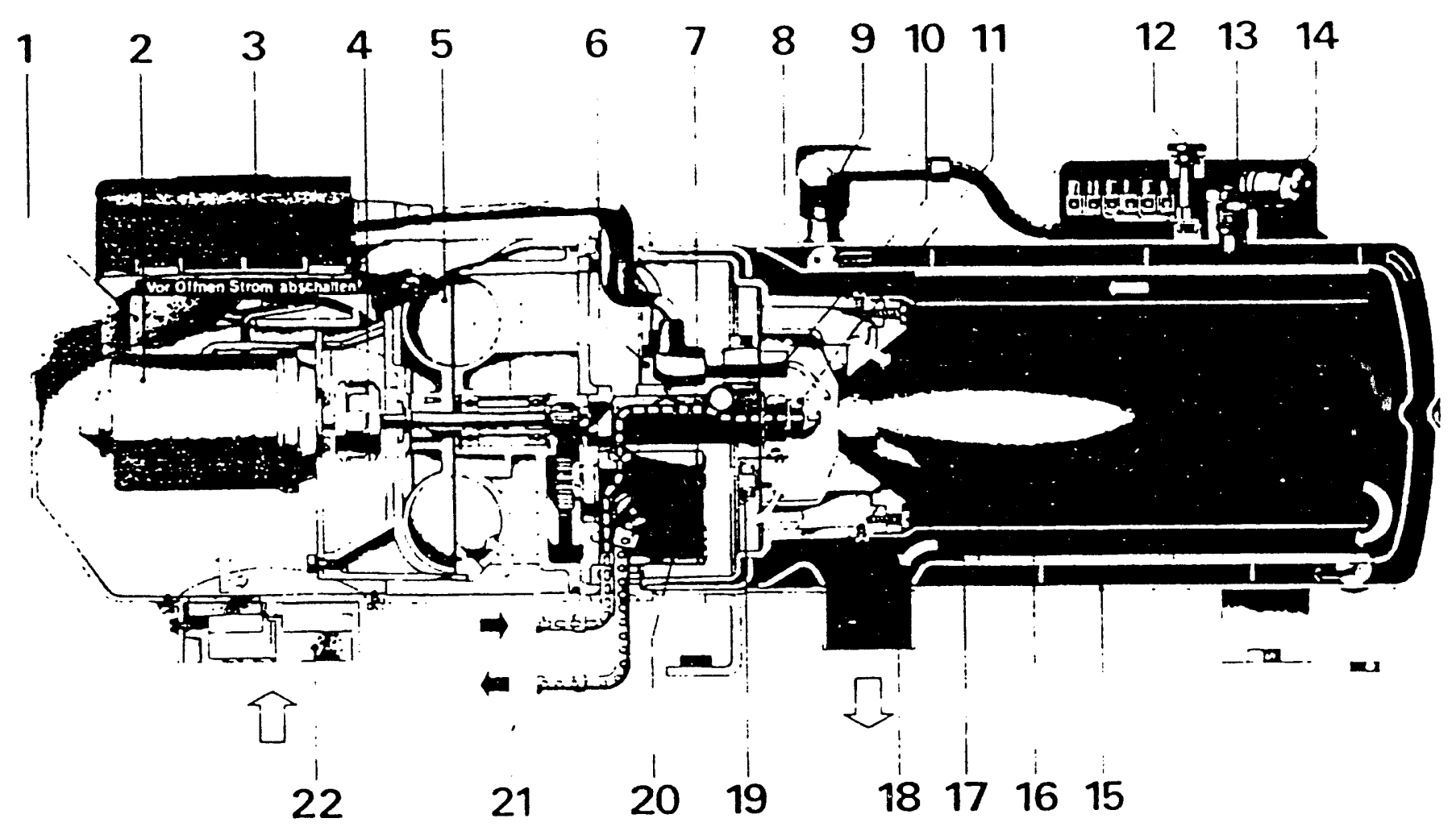

Water heaters DBW 2010

$\begin{array}{ll}1 \text { Electronic control unit } & 9 \text { Control thermostat } \\ 2 \text { Motor } & 10 \text { Ignition electrodes } \\ 3 \text { Electronic ignition unit } & 11 \text { Fuel nozzle } \\ 4 \text { Clutch } & 12 \text { overheat fuse } \\ 5 \text { Combustion air fan } & 13 \text { Control thermostat } \\ 6 \text { Solenoid valve } & 15 \text { overneat protection } \\ 7 \text { Electrode holder } & 15 \text { Heat exchanger } \\ 8 \text { Water pipe } & 16 \text { Combustion chamber }\end{array}$

17 Combustion air swirler

18 Exhaust outlet

19 Flame detection photocel

20 Fuel pump

21 Fuel pipes

22 Combustion air intake with adjusting shutter

- dependent on model

FIGURE 9: WEBASTO UNIT WITH BURNER ATTACHED. 

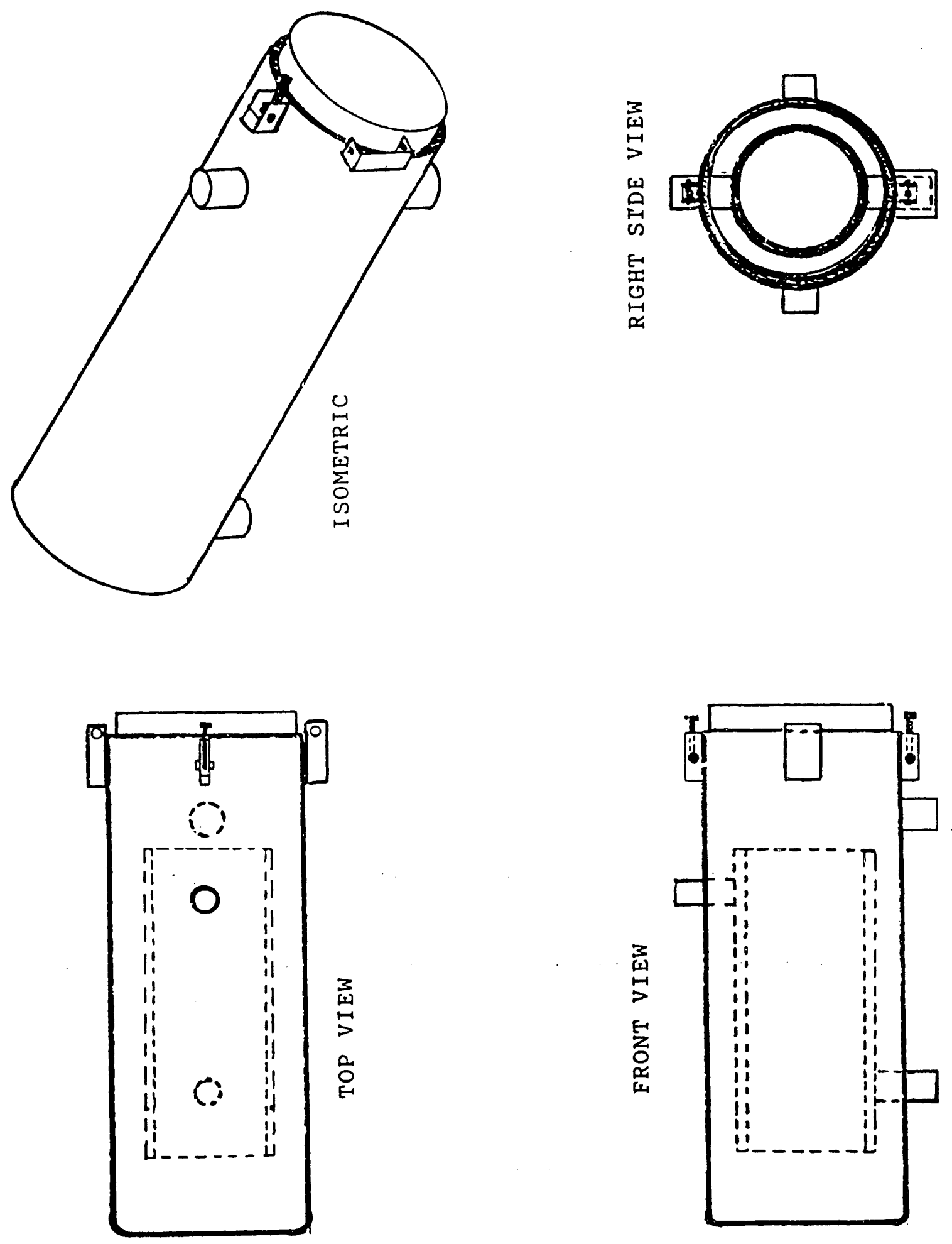

م 
The results from the test of Prototype 8 showed great improvement over all previous prototypes. It came very close to the results of the Webasto heat exchanger, but was a little slower in the time it took to reach the upper temperature of 180 degrees. A plot of the performance of this model when compared to the Webasto can be seen in Figure 11. It was determined that the reason for the slower heating time was due to the fact that excessive amounts of thermal energy were being lost through the outside shell. Efforts to capture the thermal energy being lost resulted in the design of Prototype 9. Prototype 9 (shown in Figure 12) is a modified version of Prototype 8. The only difference between this model and the previous model is that an additional water jacket has been added to the outer shell to capture some of the heat which was escaping. This addition can be seen in Figure 12. The plot of the change in temperature versus time shown in Figure 13 compares the performance of Prototype 9 to the Webasto unit.

This final prototype exceeded the performance of a commercially available Webasto DBW-2010 using the same commercial burner as the one used in the Webasto unit. The time required to raise the heater fluid temperature by $120^{\circ} \mathrm{F}$ was $23 \%$ less ( 20 minutes compared to 26 minutes) for Prototype 9 compared to the commercially available unit. One final minor modification made to Prototype 9 was to increase the length of the outside water jacket. This change was made to effect a further increase in the efficiency of the unit and to eliminate any safety hazard caused by hot, exposed surfaces. This modification is shown in Figure 14.

Prototype 9 was also tested with the coolant waie: flowing counter to the direction of flow of the combustion gases. The previous comparative testirg with the Webasto unit had the flow parallel to the combustion gases. The results $f \subset r$ these two test conditicns are shown in Figure 15. It is seen that the counter flow conditions were not as efficient.

During the final quarters of the project, a diesel fuel heat exchanger was also designed, fabricated and tested. The purpose of this portion of the auxiliary heater system was to preheat engine fuel to prevent cold weather separation of the fuel and the subsequent clogging of fuel filters by gelled wax. This fuel heat exchanger geometry is shown in Figure 16. It is simply a single-pass design on both the hot and cold sides. The cold side is simply a copper tube through which fuel flows on its way to the engine fuel filter. The shell or hot side is constructed of P.V.C. tubing and fittings. The fluid used to heat the fuel is from the outlet of the Prototype 9 heat exchanger. This unit raised the temperature of diesel fuel $60^{\circ} \mathrm{F}$ in 9 minutes as the fluid temperature for the auxiliary heater increased from $122^{\circ} \mathrm{F}$ to $188^{\circ} \mathrm{F}$. A flow rate comparable to the maximum expected fuel consumption of a diesel engine was used. The incorporation of the fuel heat exchanger represents a capability not presently available with commercially available heaters. 
DPROTOTYPE $8 \quad \square$ WEBASTO

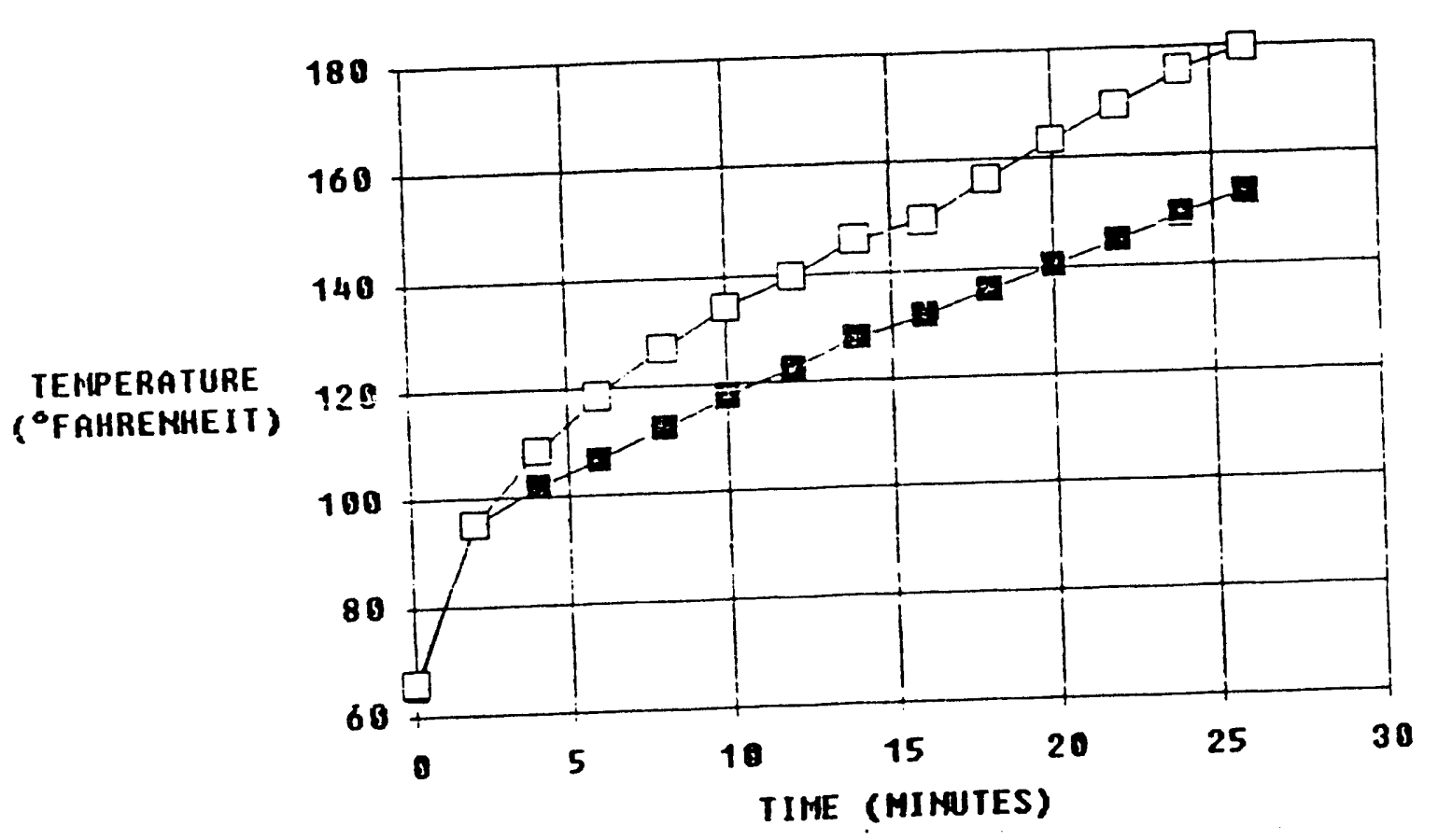

FIGURE 11: RESULTS OF PROTOTYPE 8 COMPARED TO WEBASTO 

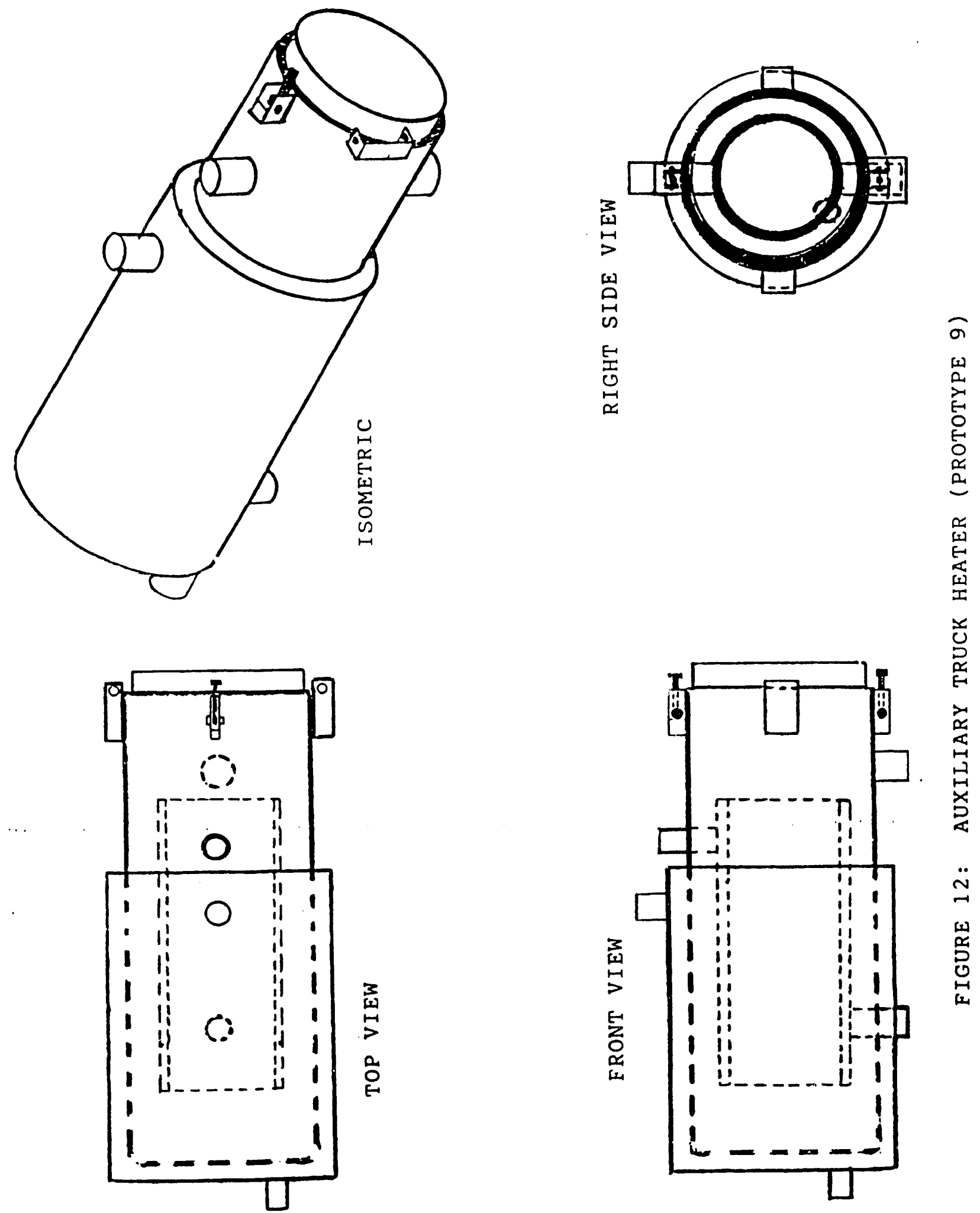
PROTOTYPE $9 \square$ WEBASTO

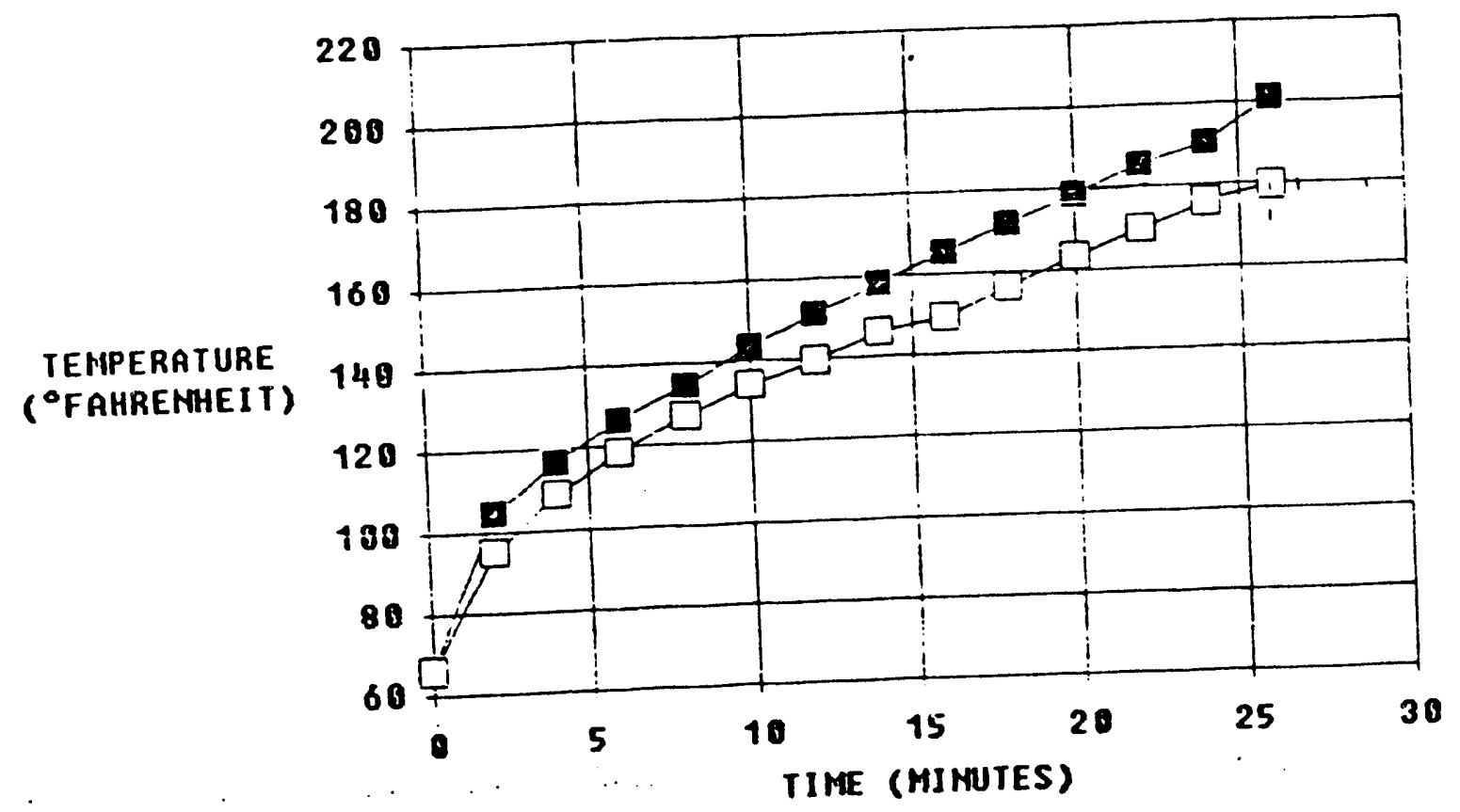

FIGURE 13: RESULTS OF PROTOTYPE 9 COMPARED TO WEBASTO 

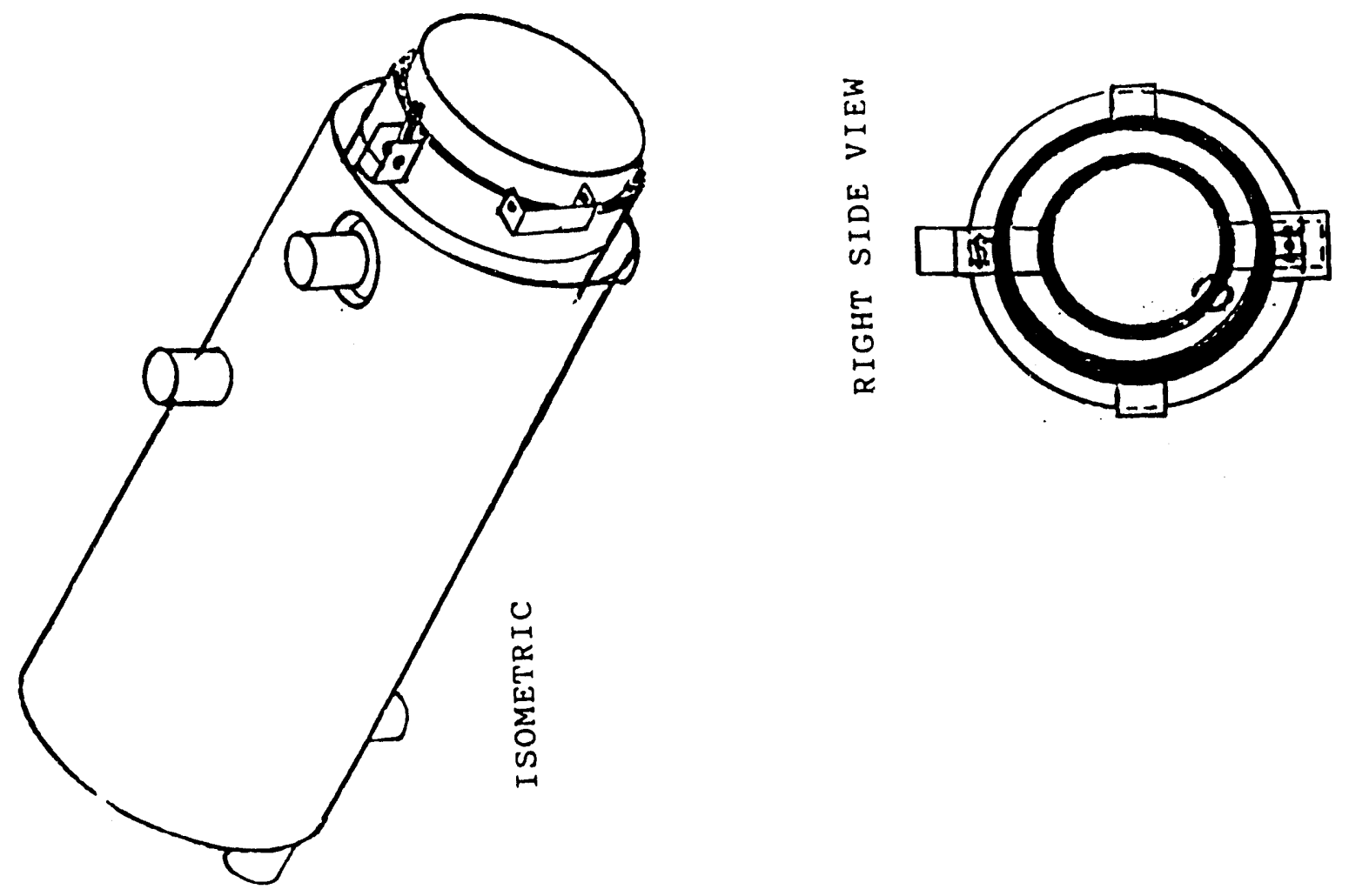

告
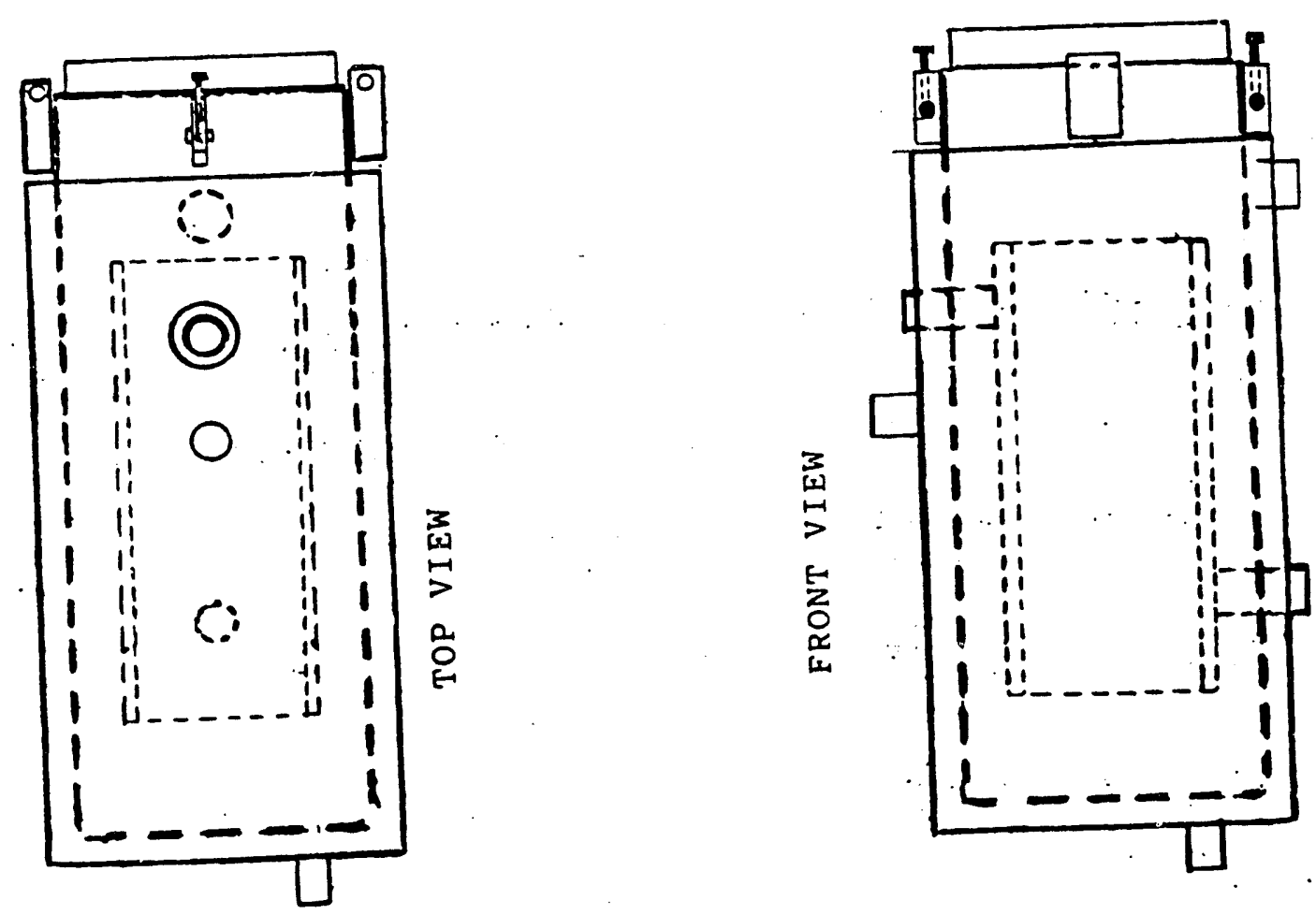


\section{PARALLEL FLOW $\square$ COUNTER FLOW}

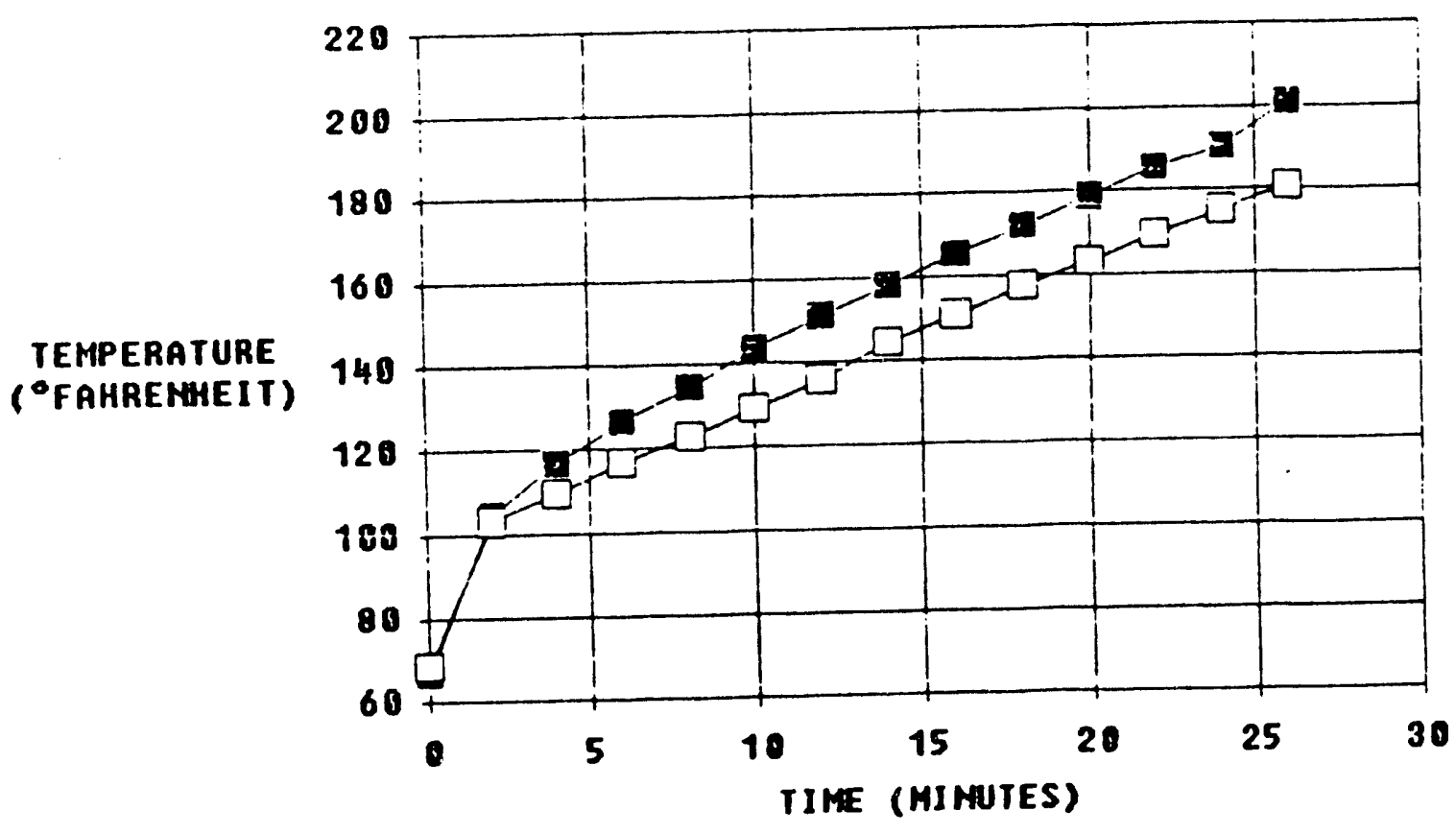

FIGURE 15: PROTOTYPE 9 COUNTER VERSUS PARALLEL FLOW 


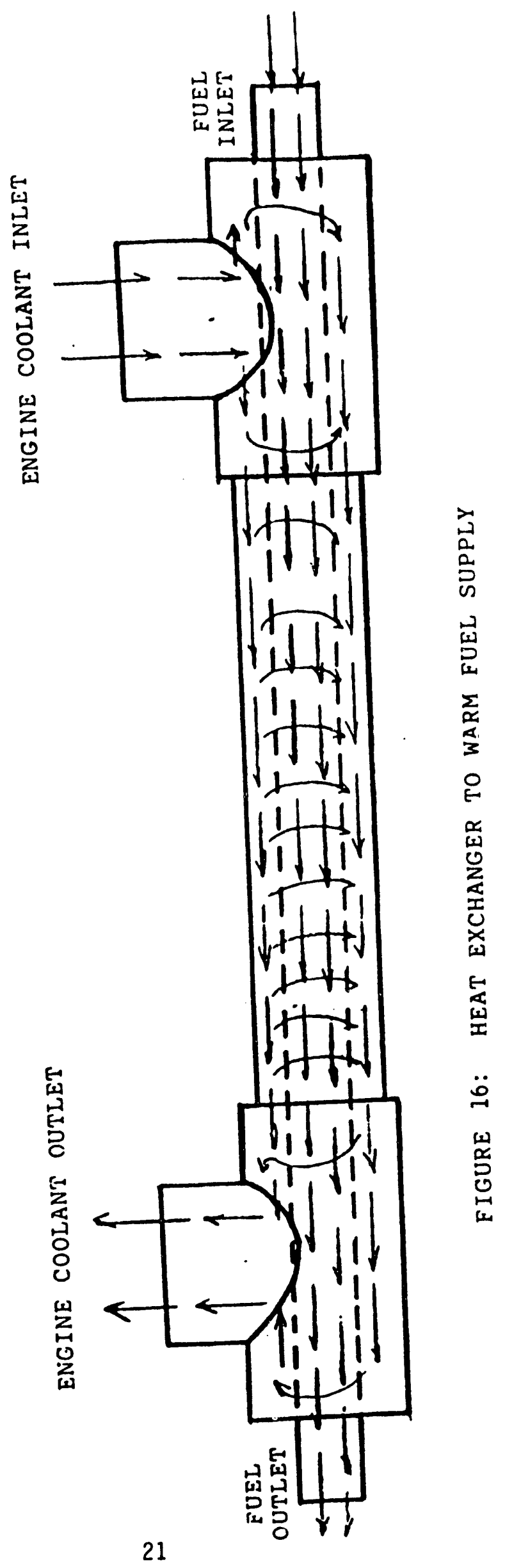


It was also determined that the Prototype 9 auxiliary heater could operate at $85^{\circ}$ F for approximately 6 hours on a fully charged 12 volt marine battery rated to deliver 500 cold cranking amps. This operating time would be significantly reduced at sub-freezing temperatures. Accordingly, additional battery capacity would be needed for extended operation.

Complete working drawings for the final prototype heat exchangers for both the auxiliary heater and engine fuel preheating are shown in Appendix I.

\section{Conclusions}

- The ideas contained in the Easterly patent were found to be technically feasible and were demorstrated via a working prototype.

- Nine different versions of prototype heaters were designed, constructed and tested. All designs were based on the ideas and principles outlined in the Easterly patent. Each successive version incorporated design and fabrication improvements relative to the previous version.

- The final version, Prototype 9, utilized a multiple water jacket design to capture additional heat from the combustion gases prior to exhausting to the atmosphere. This final prototype exceeded the performance of a commercially available Webasto DBW-2010 using the same commercial burner as the one used in the Webasto unit.

- A prototype heat exchanger for preheating engine fuel was designed, fabricated and tested as part of the auxiliary heater system.

- The final prototype system is simple enough in materials and design that it can be manufactured at a reasonable cost. Of course actual manufacturing cost would be very sensitive to the production volume.

- The electrical power requirements of such an auxiliary heater are significant if the unit is to be used for prolonged periods of time such as for heating the cab of a parked vehicle. Some provision for heating the batteries with fluid from the auxiliary heater would be highly desirable in extremely cold weather.

There are already several commercially available units which utilize some of the ideas contained in the Easterly patent. One of these units was used in comparative 
testing and found to be a well designed and highly reliable unit. The availability of this and other units should be considered in any subsequent efforts to commercialize the Easterly heater. It might be desirable to consider commercializing only the fuel pieheating unit to be used with presently availabie units which do not have provisions for fuel preheating.

- There is a need for testing any auxiliary heating under actual driving conditions in extreme winter weather conditions. This type of testing was too expensive to be carried out within the limited scope of this project. There was also no daia in the technical literature provided with the Webasto unit to indicate how well the unit operates at sub-zero temperatures. It would seem that initial starting of the burner in very cold weather could be a potential problem. 
Appendix I.

Working Drawings of Final System Prototype of

Easterly Auxiliary Truck Heater 


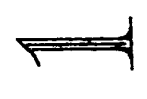

II

II

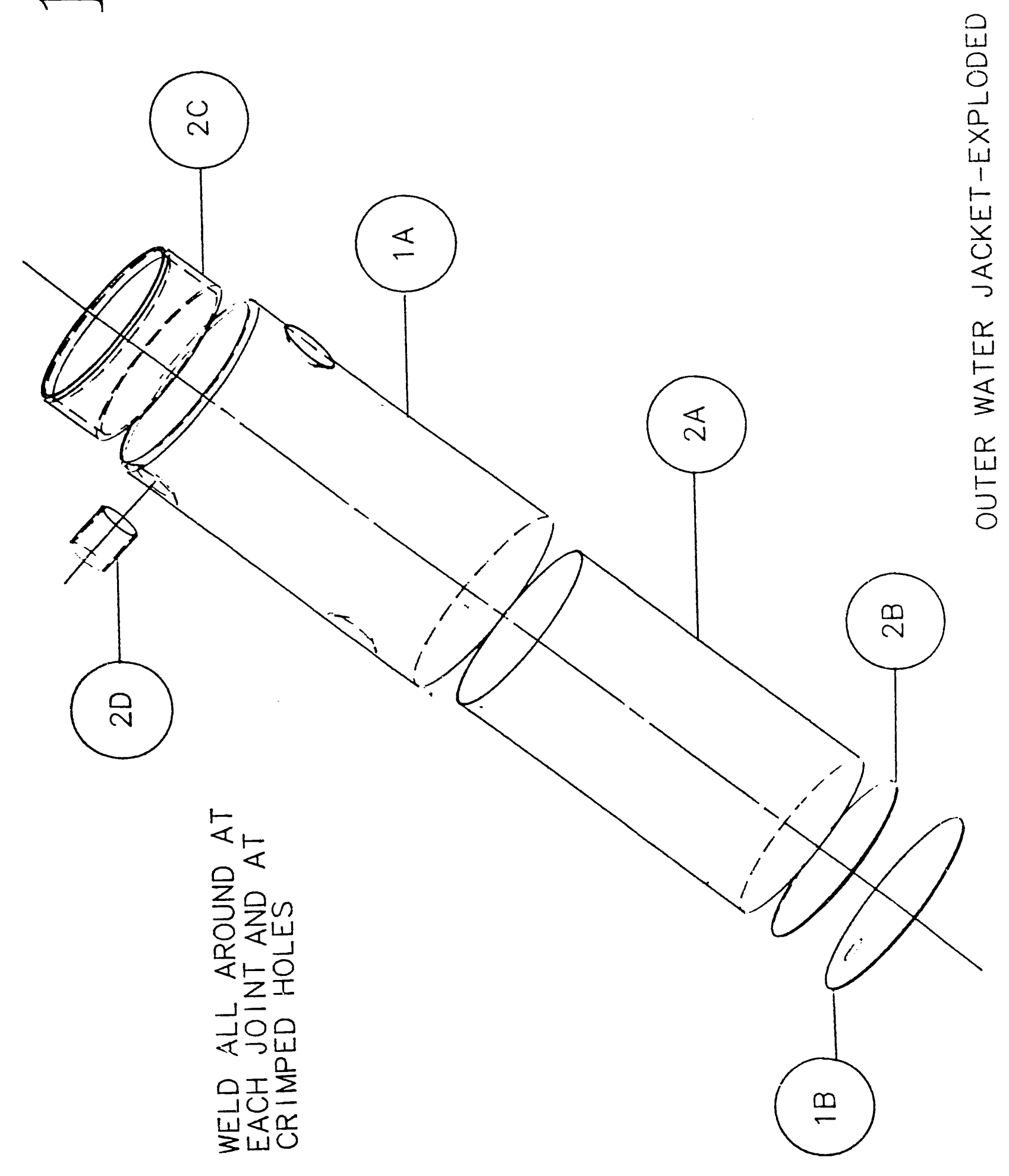

II

II

II

II

II

II

I

I

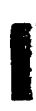

I 
1

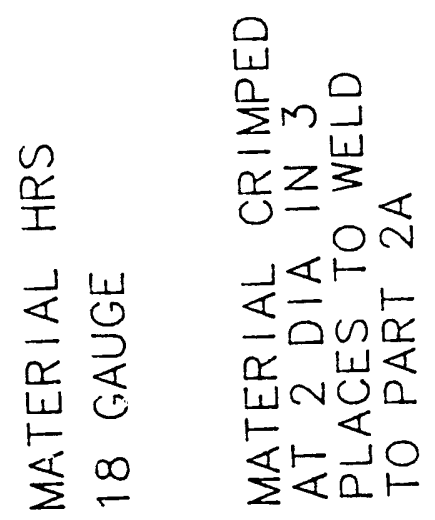

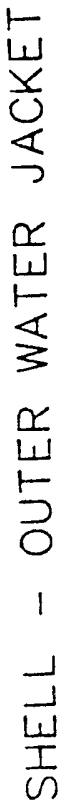

$\begin{array}{llll}\pi & 0 & n & 0 \\ 0 & 0 & N & 0\end{array}$

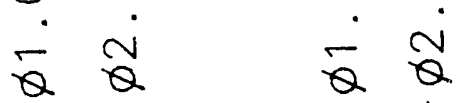

II
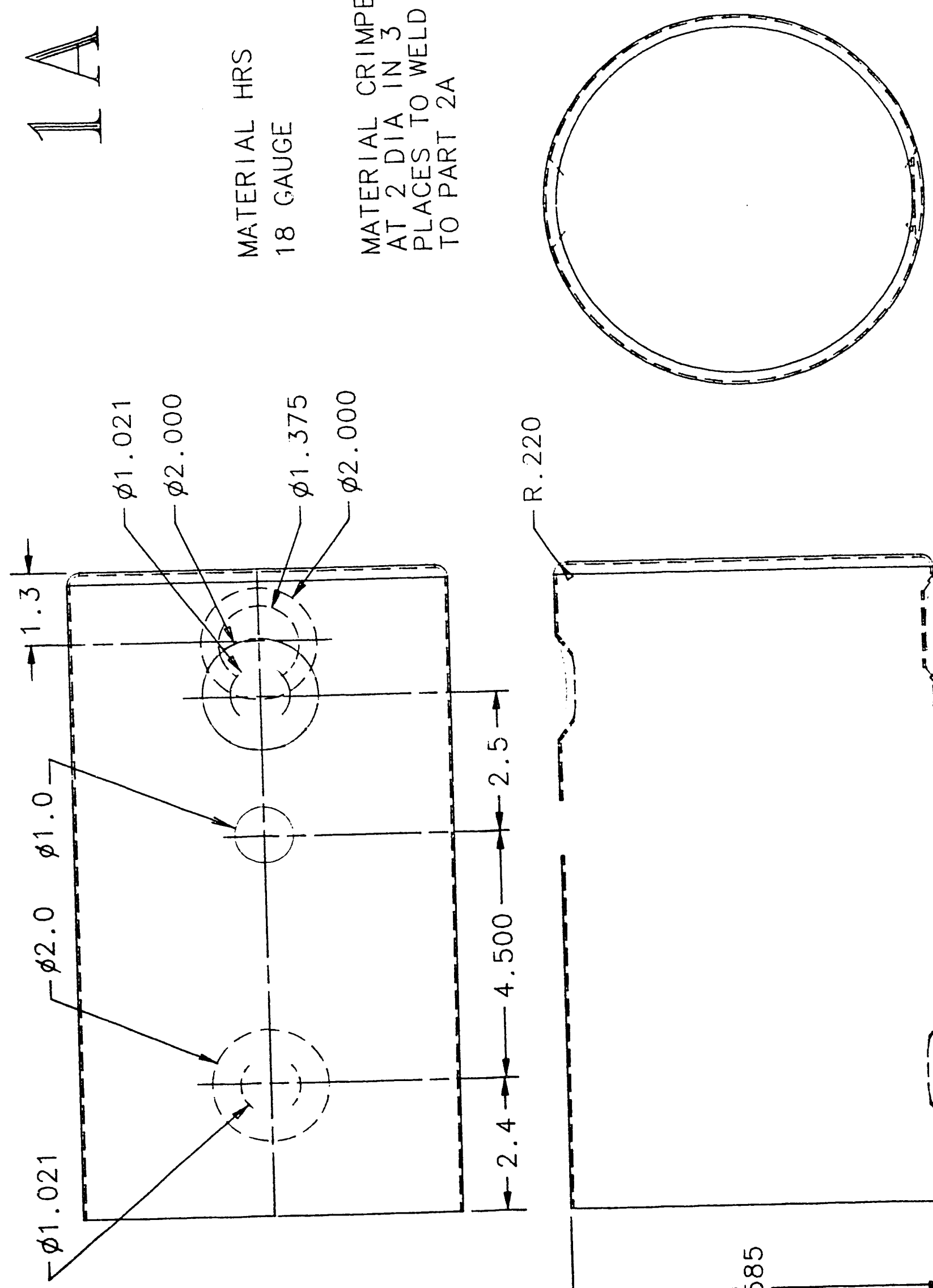

$\frac{J}{5}$
$\frac{1}{n}$
$\frac{x}{w}$
5
$\frac{5}{0}$

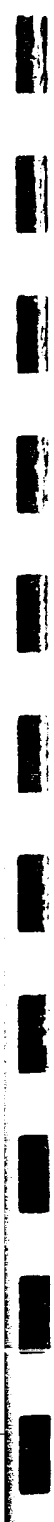

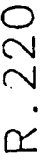

II

I

I

I

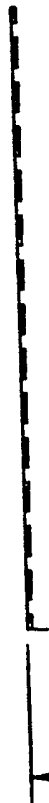

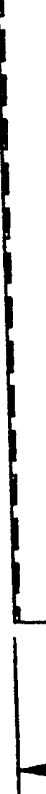

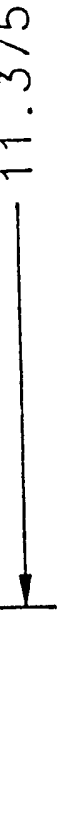


$\| \mathrm{QP}$

II

II

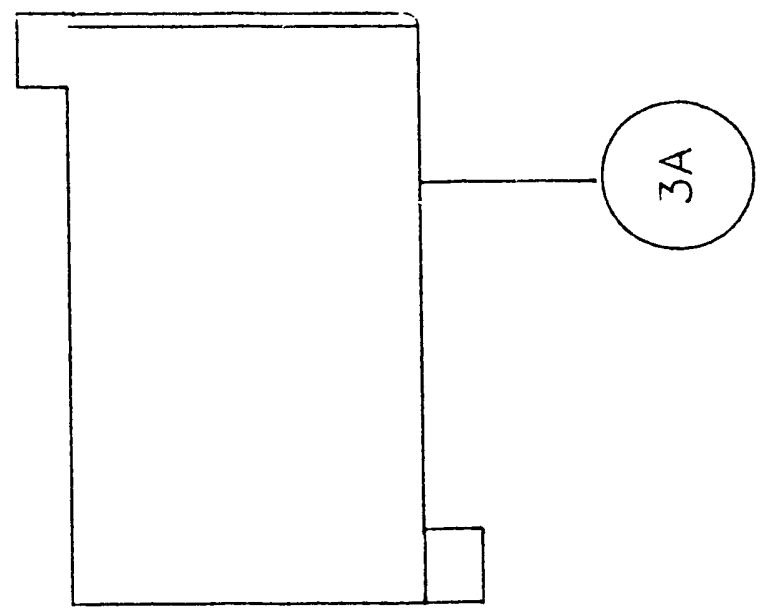

II

II

II

II

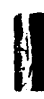

II

II

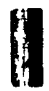

$\|$

II

II
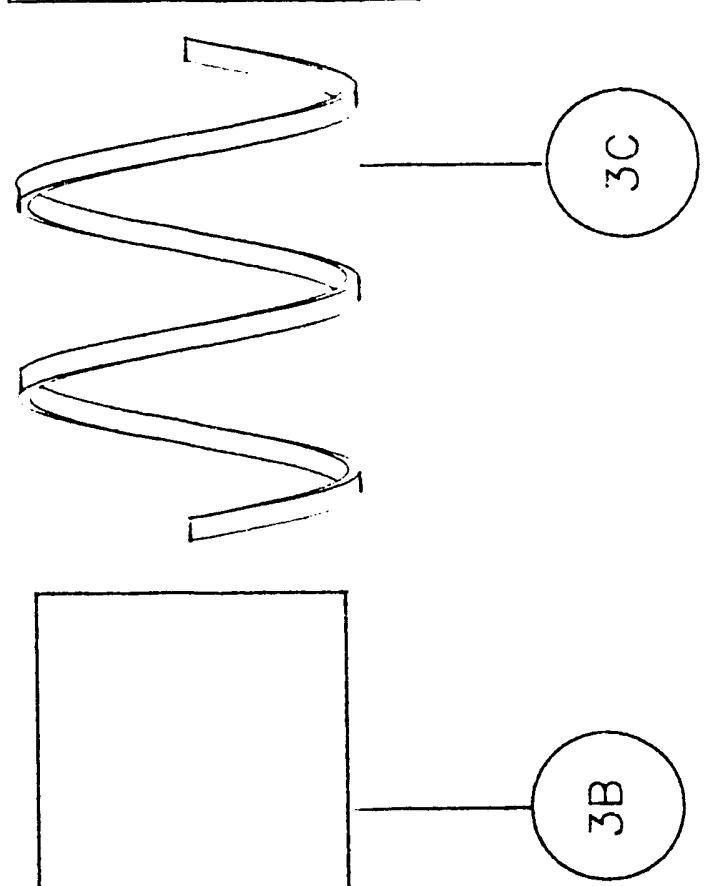

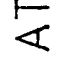

0
2
$2 \frac{1}{2}$

光志

ل4ا

岁尔 


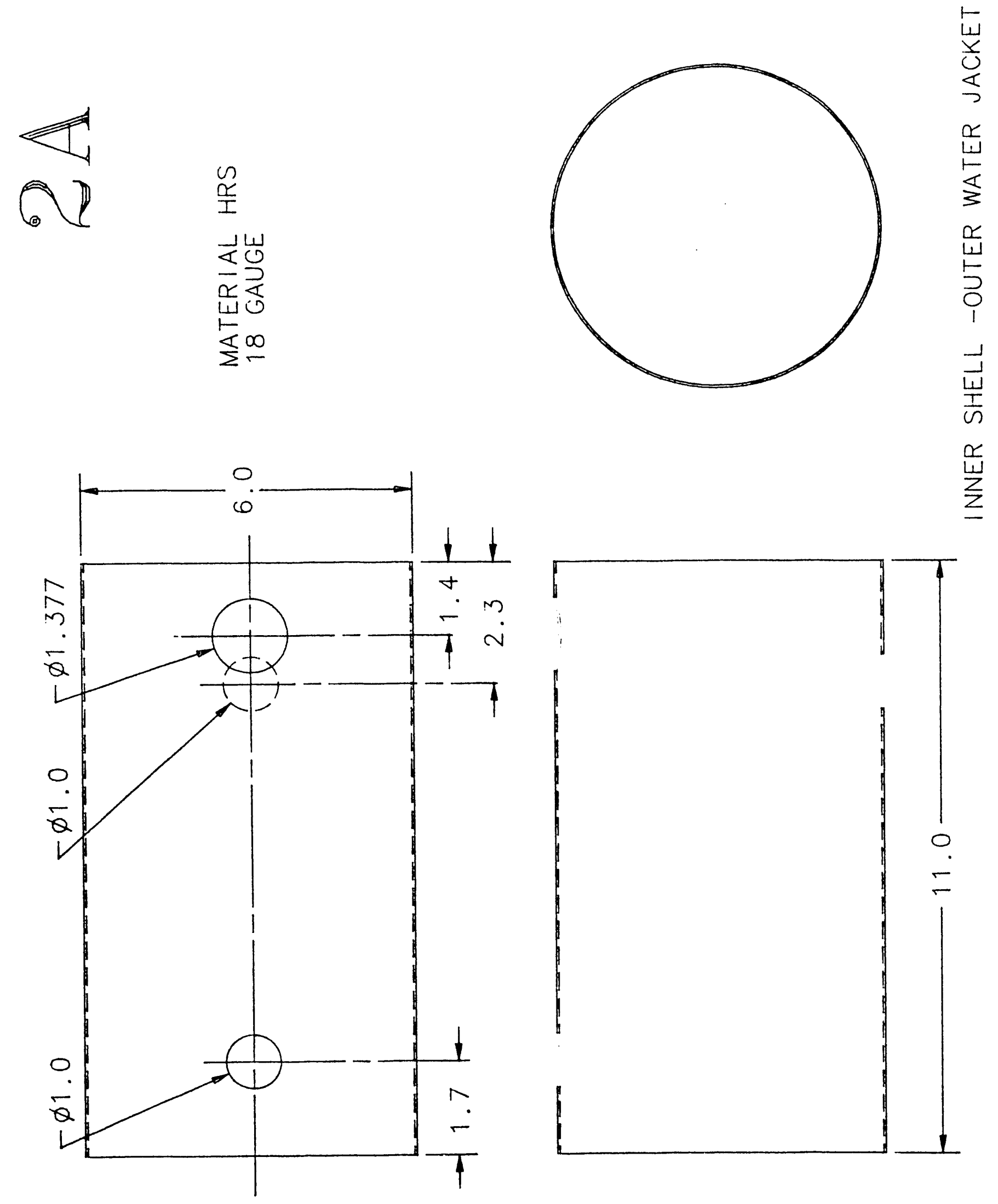




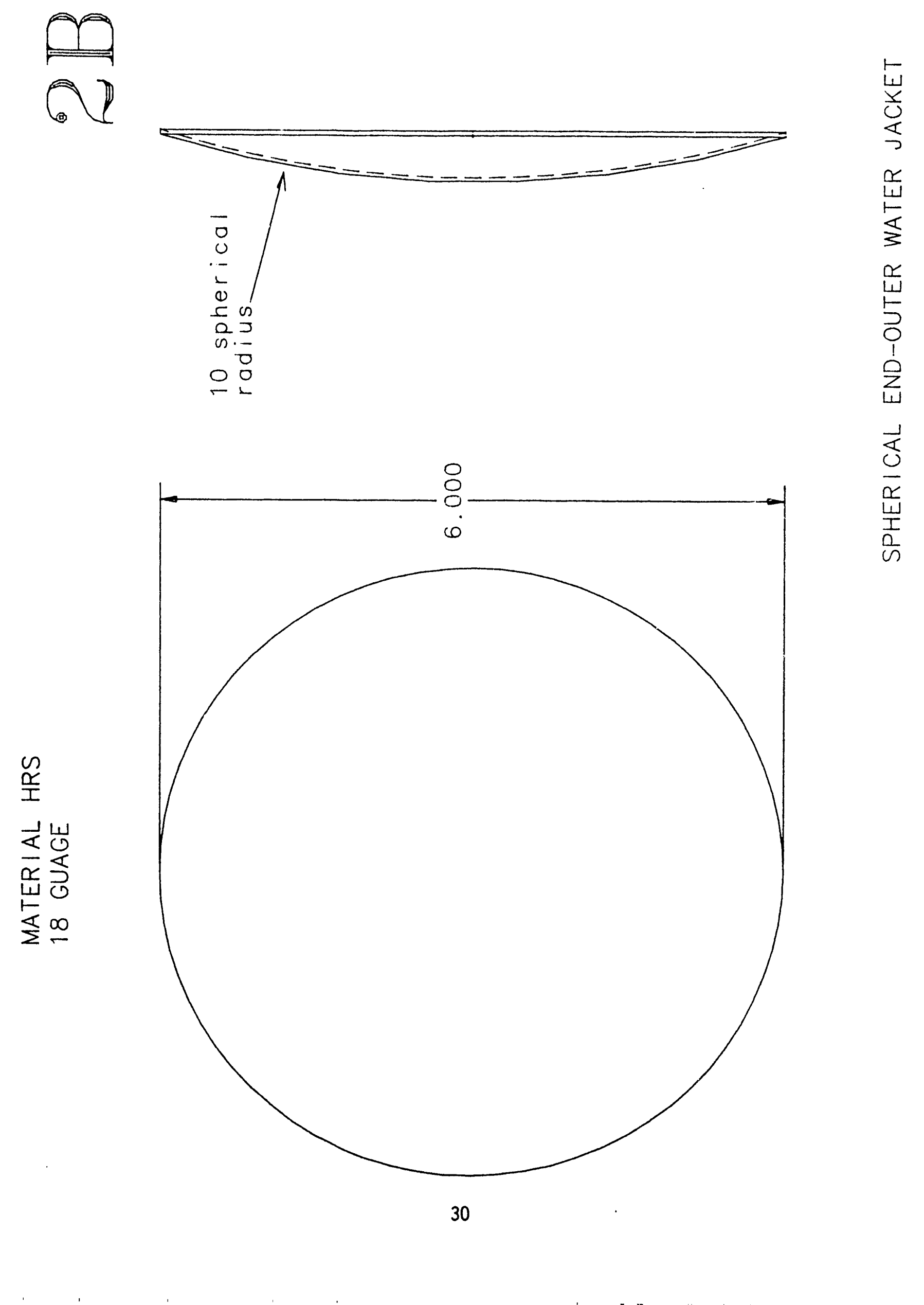



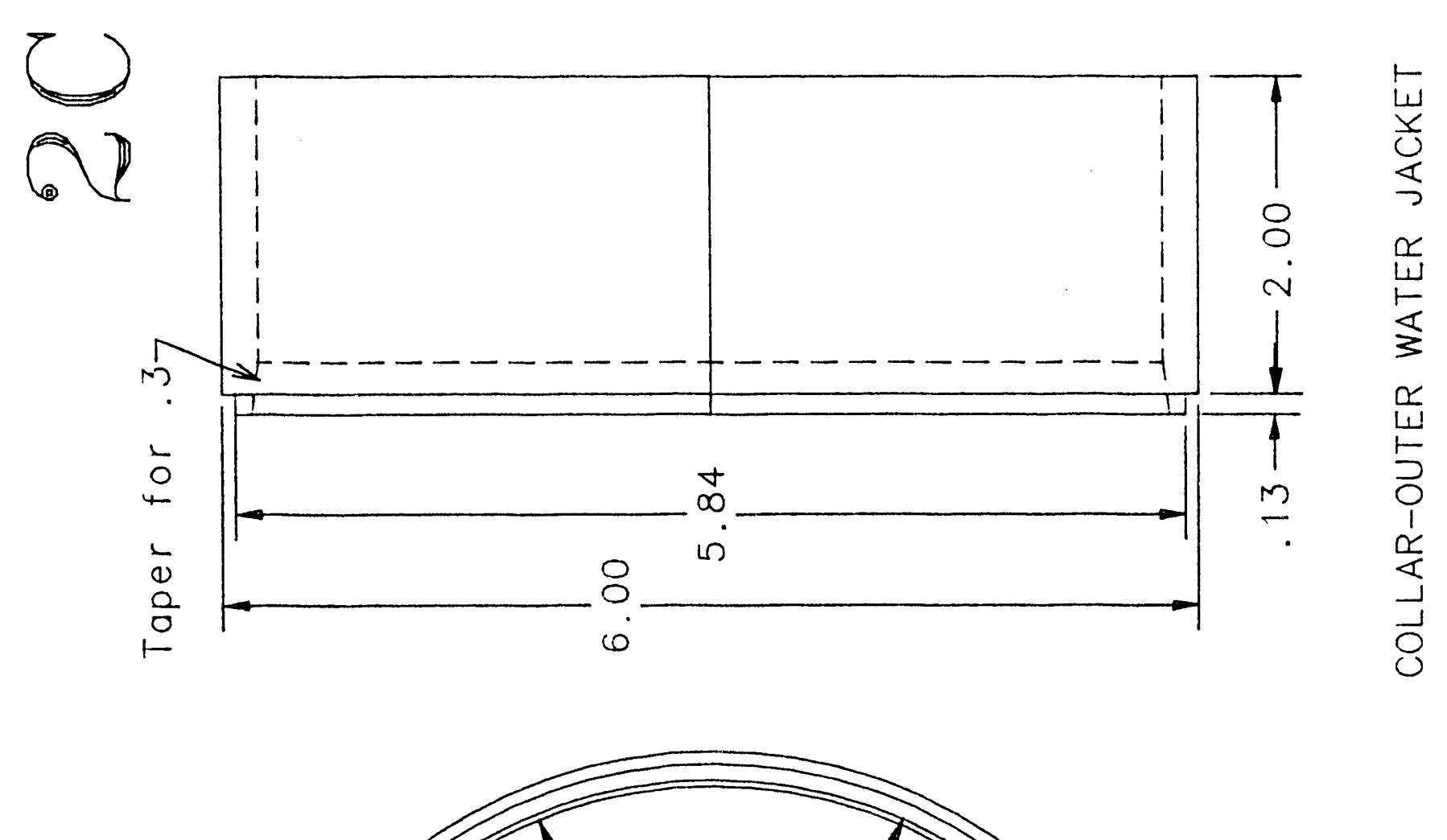

H

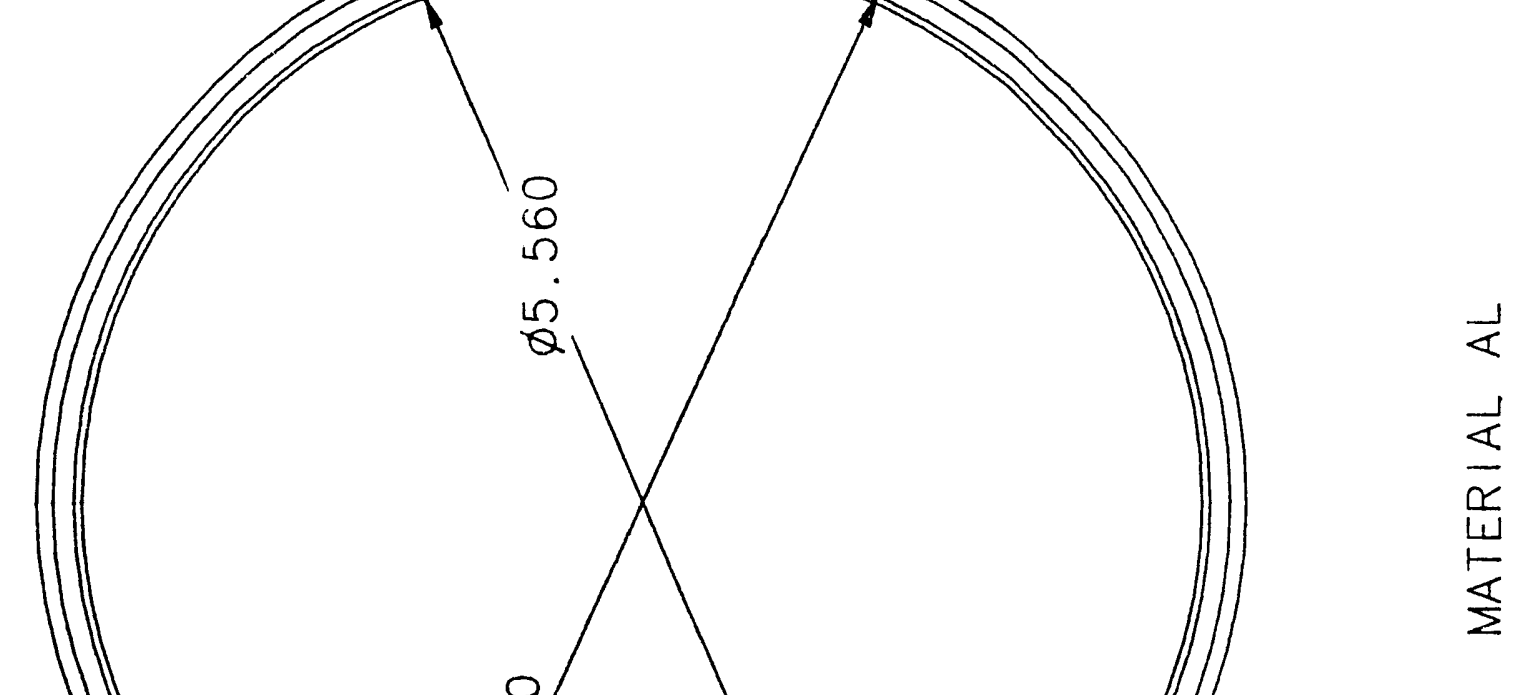

1 


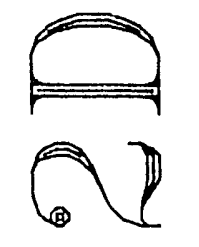

I

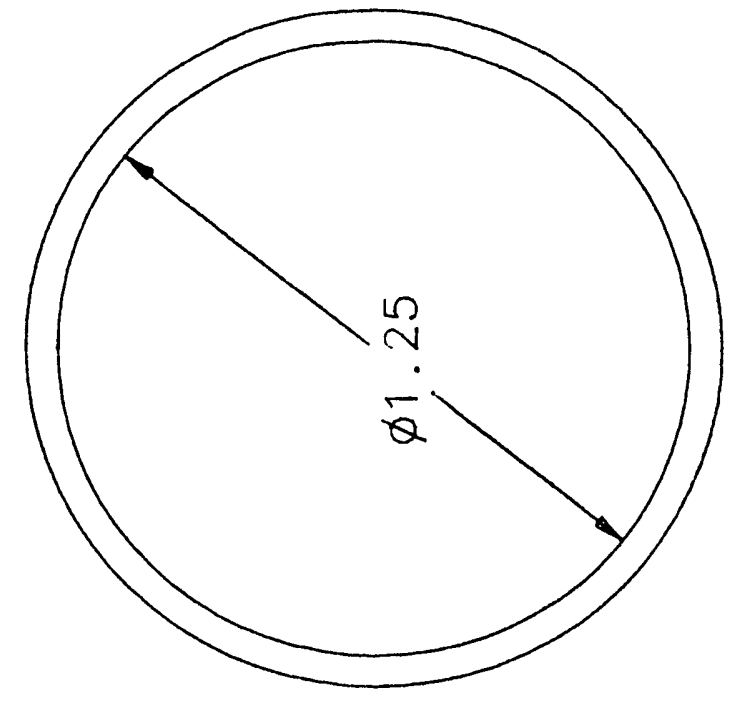

$\frac{5}{4}$

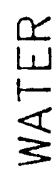

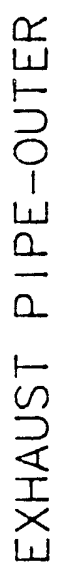

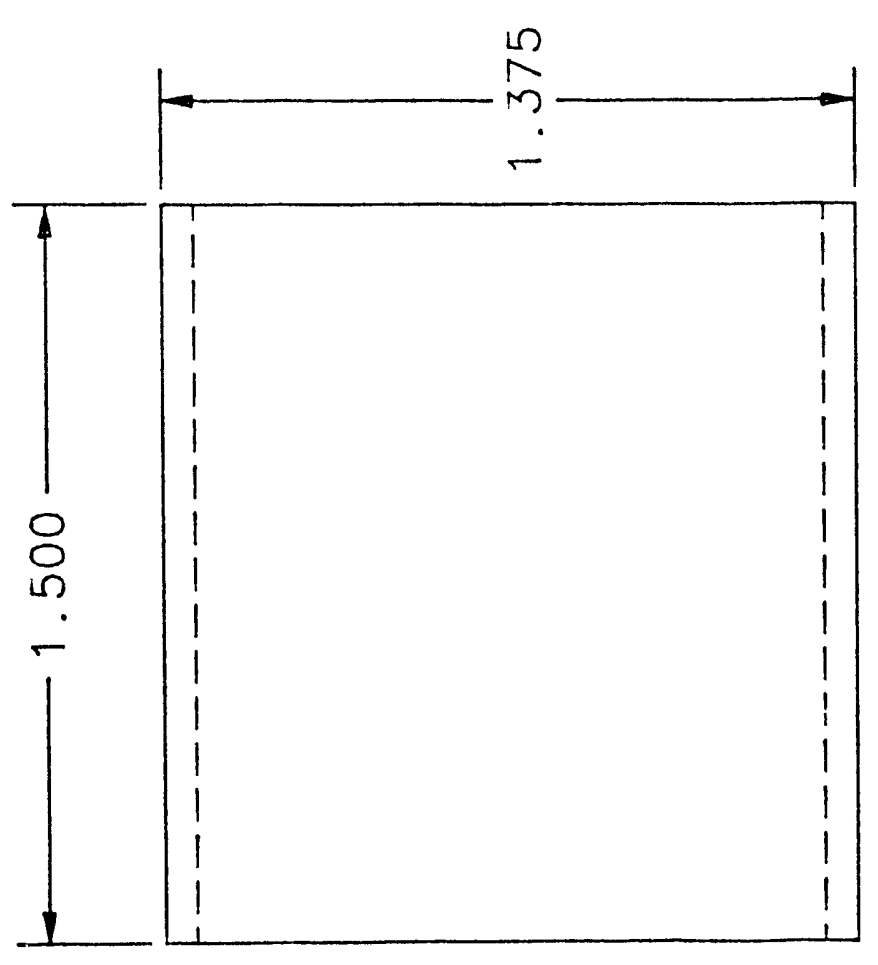



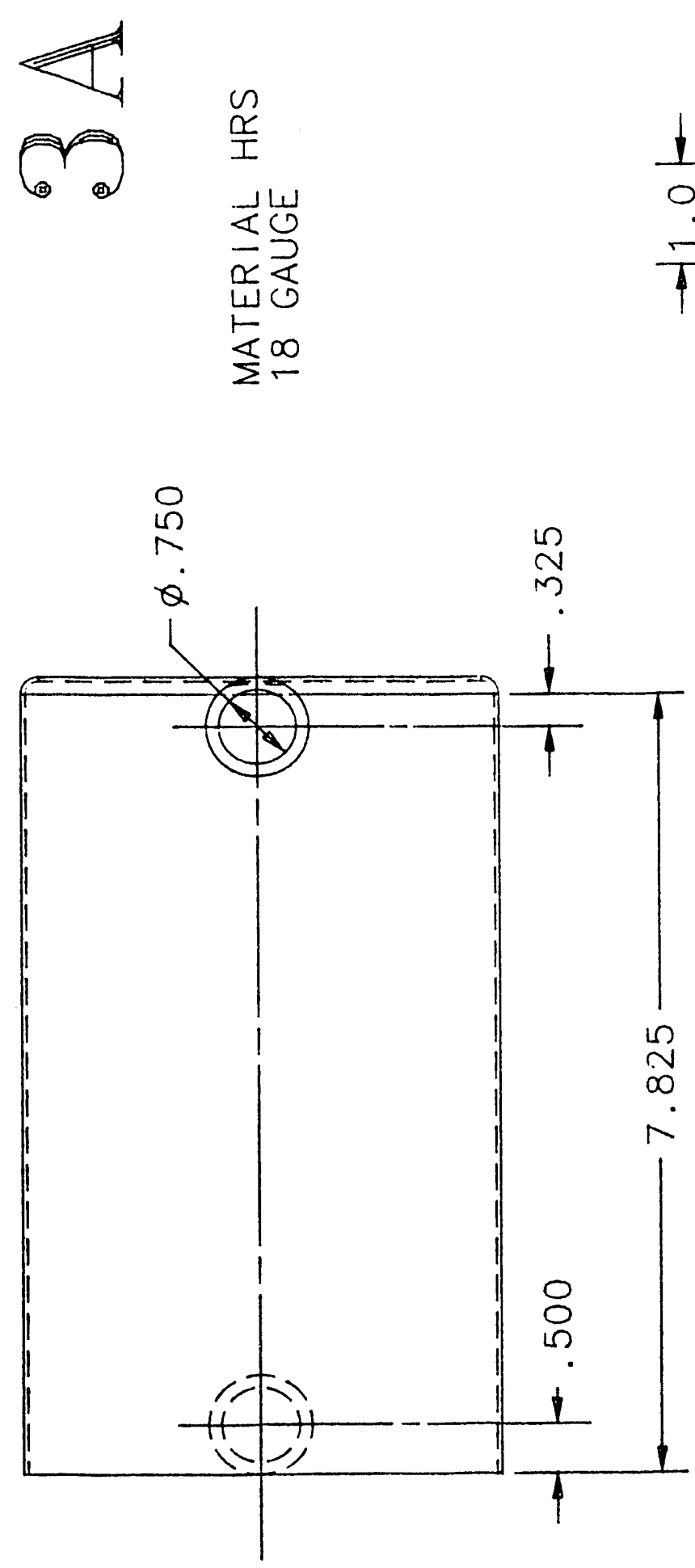
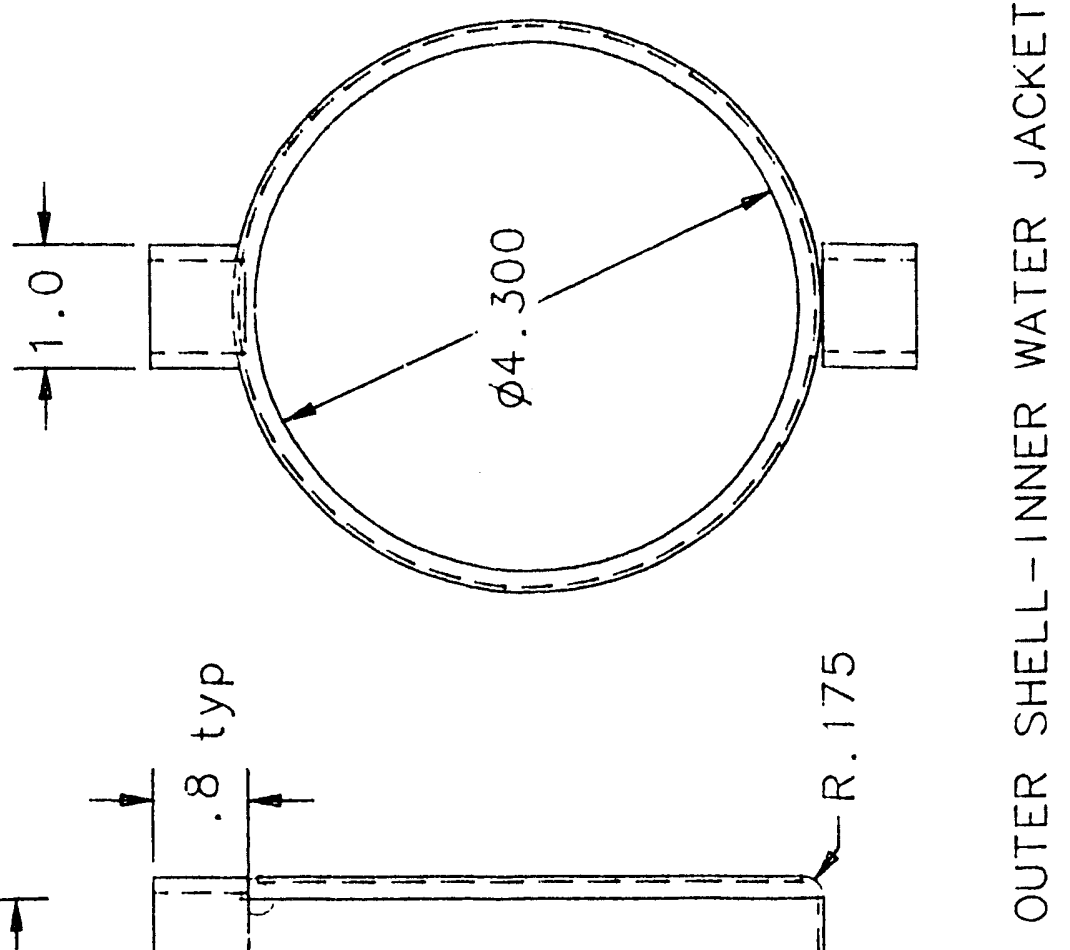


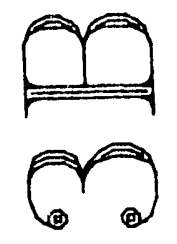

$\frac{N}{I}$

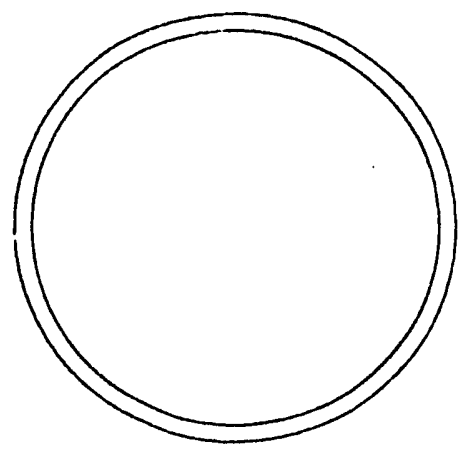

$\frac{1}{4}$

$\frac{\alpha}{5}$

$\frac{\sigma}{2}$
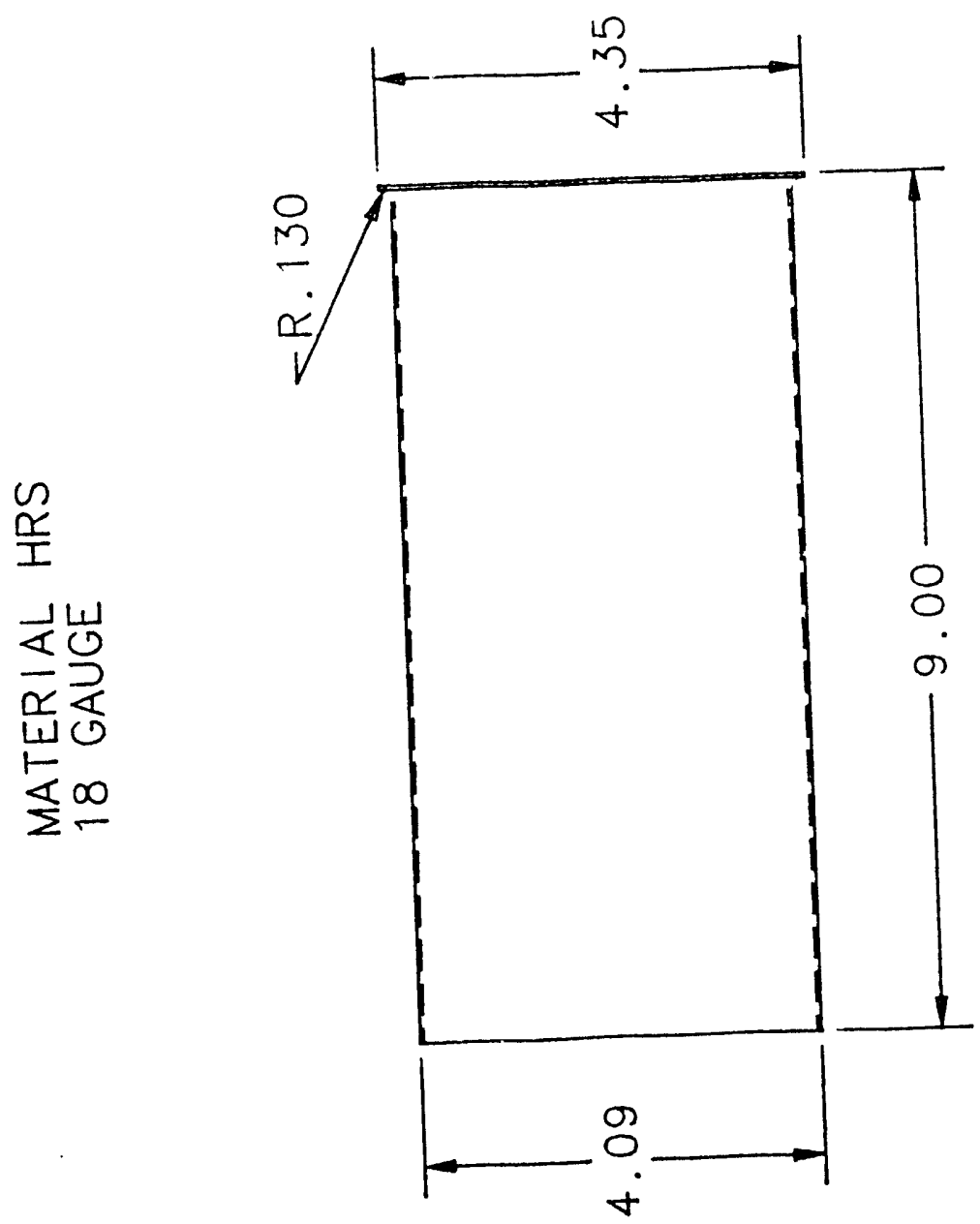

$\frac{\alpha}{z}$ 


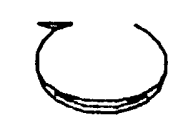

$\Leftrightarrow$

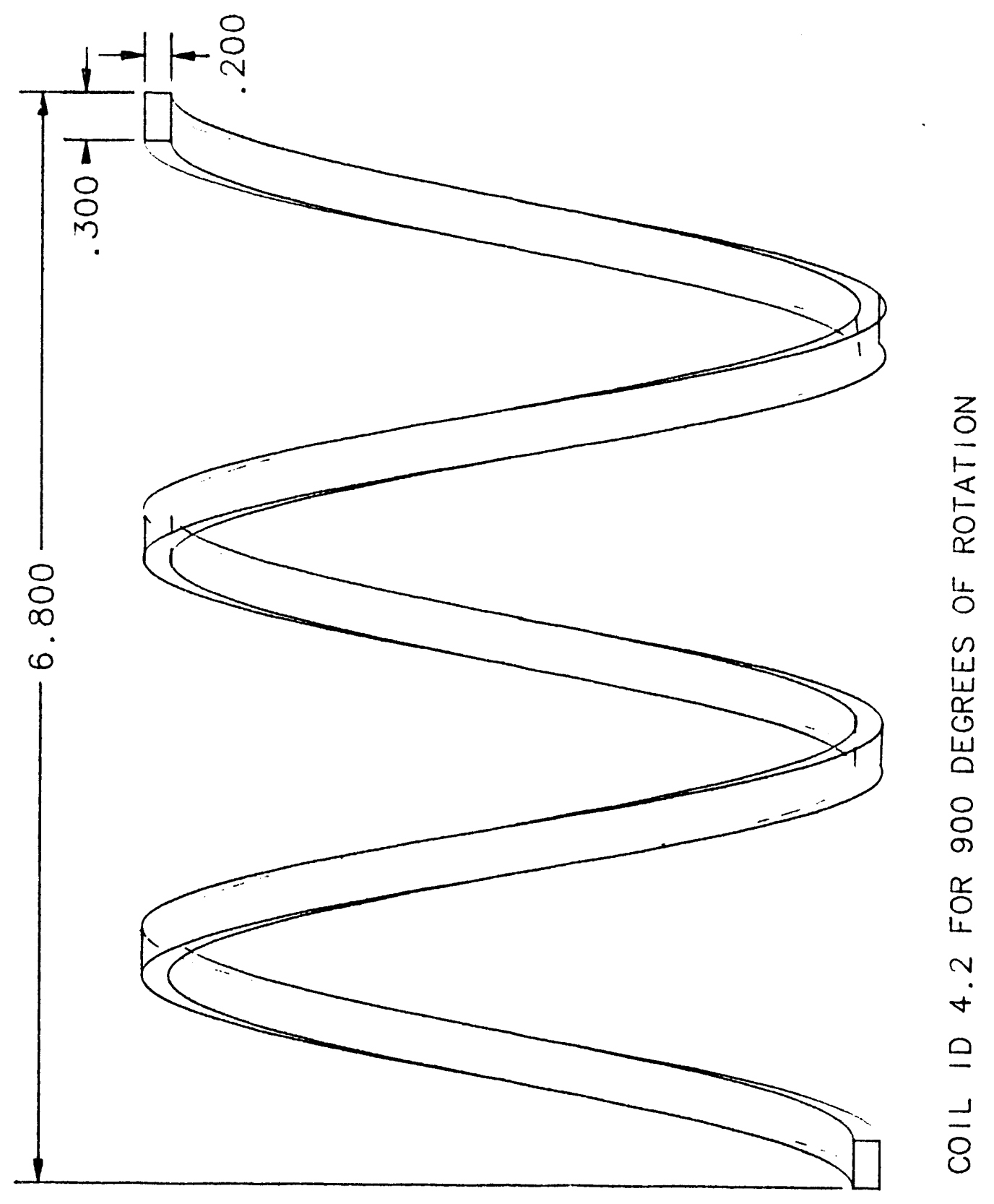




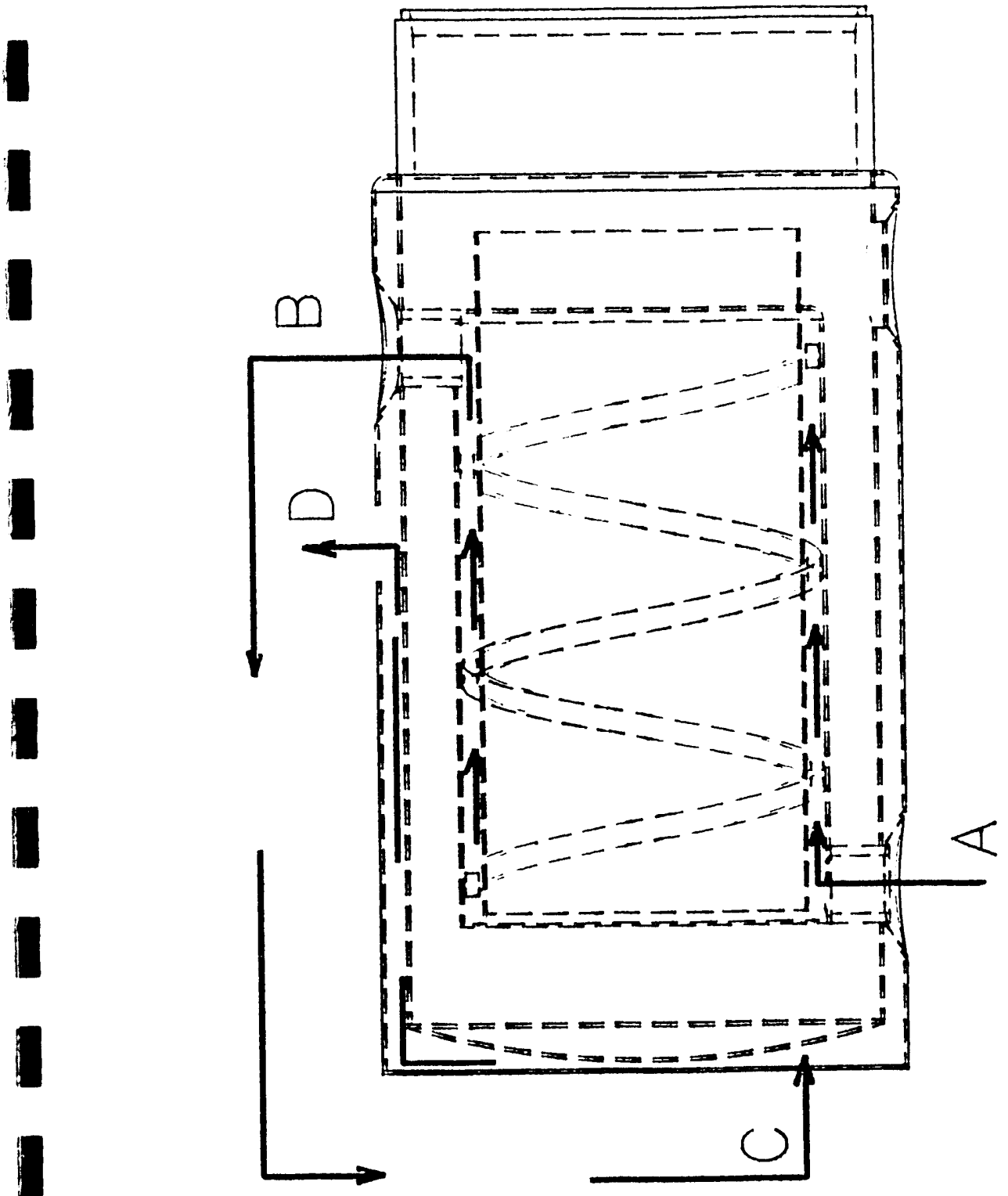

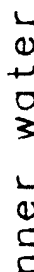

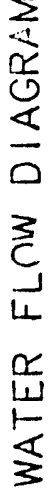

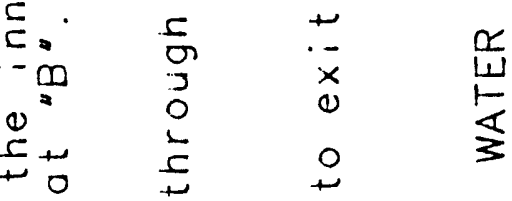

西尓 $>$

$\begin{array}{lll}0.0 & \frac{0}{0} & \frac{x}{0}\end{array}$

ᄃ民 0 ह .

$\therefore \quad \frac{0}{x}$

O.=

כ艺诺了

ᄂே兀

$\begin{array}{ccc}n-0 & 0 & 0 \\ 0 & 0 & 0\end{array}$

ס0 की

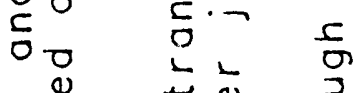

$\begin{array}{lll}0 & 1 & 0 \\ 0 & 0 & 0 \\ 0 & 0 & 0\end{array}$

- 0 O

$+\frac{1}{3}<1$

n $\stackrel{0}{0} \stackrel{0}{0} \frac{1}{0}$

एक 3 ग

등 ตับ ᄂ

ᄂ)

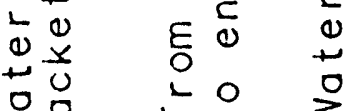

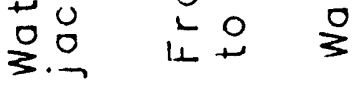

$\therefore \quad r$ 


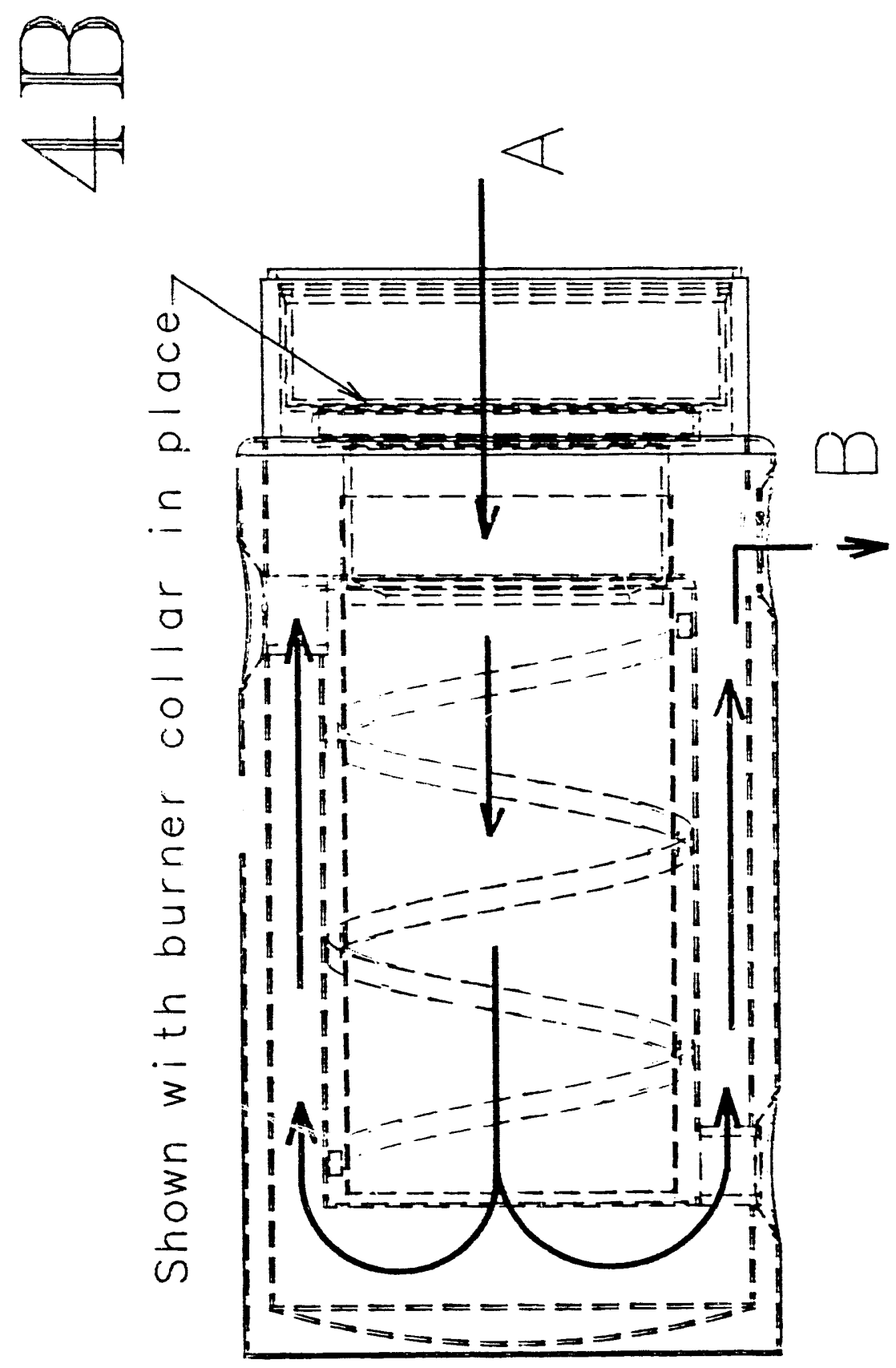




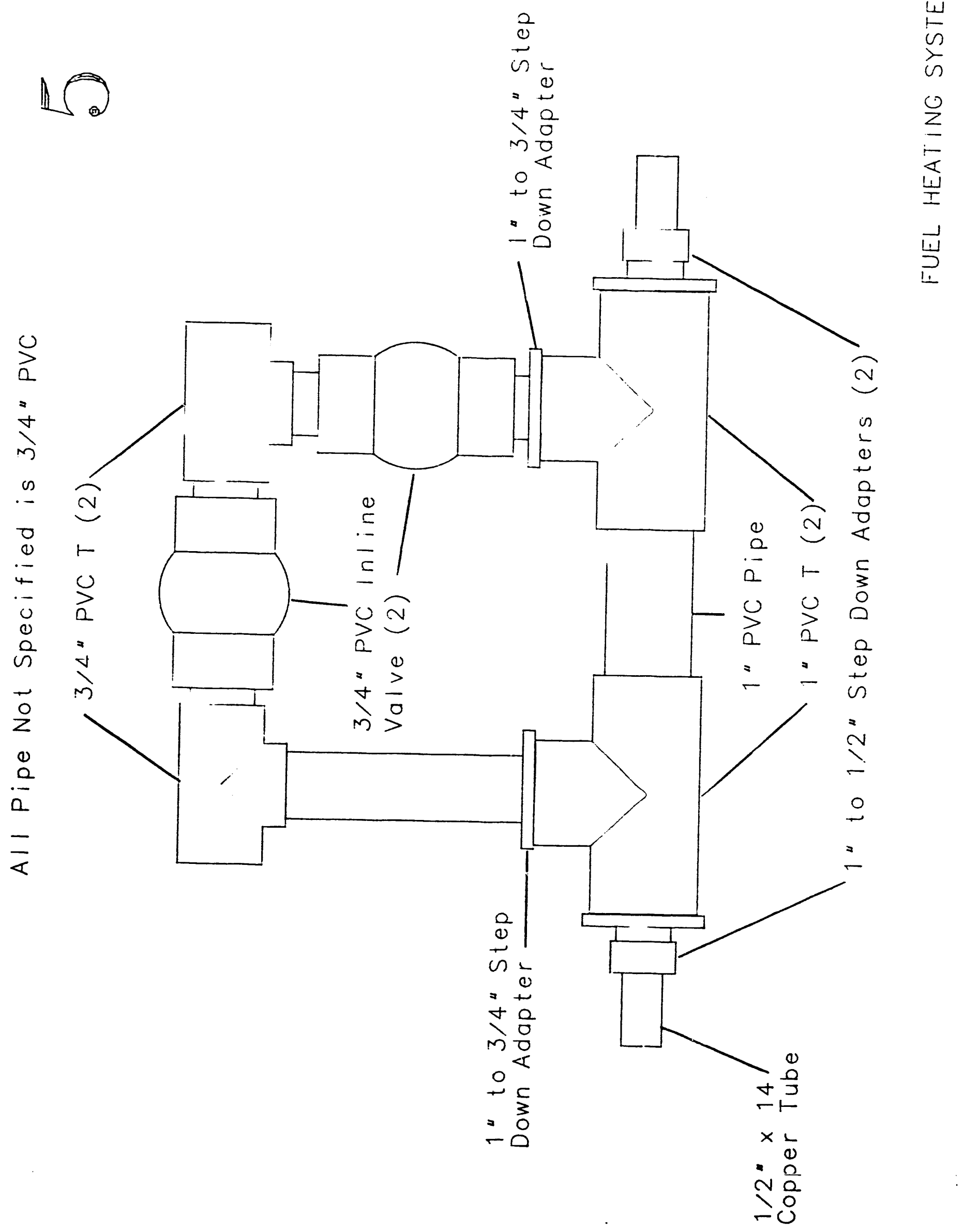




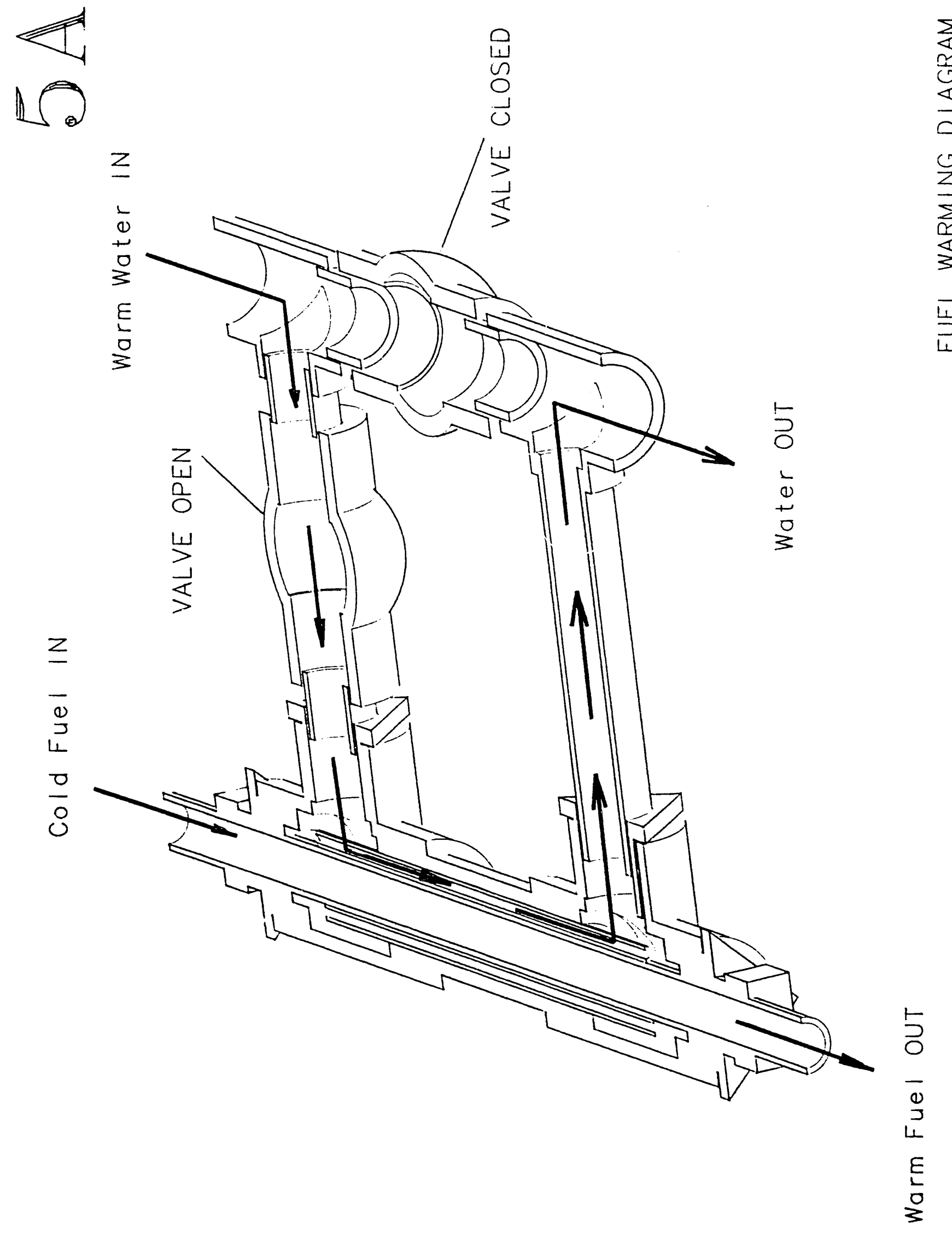



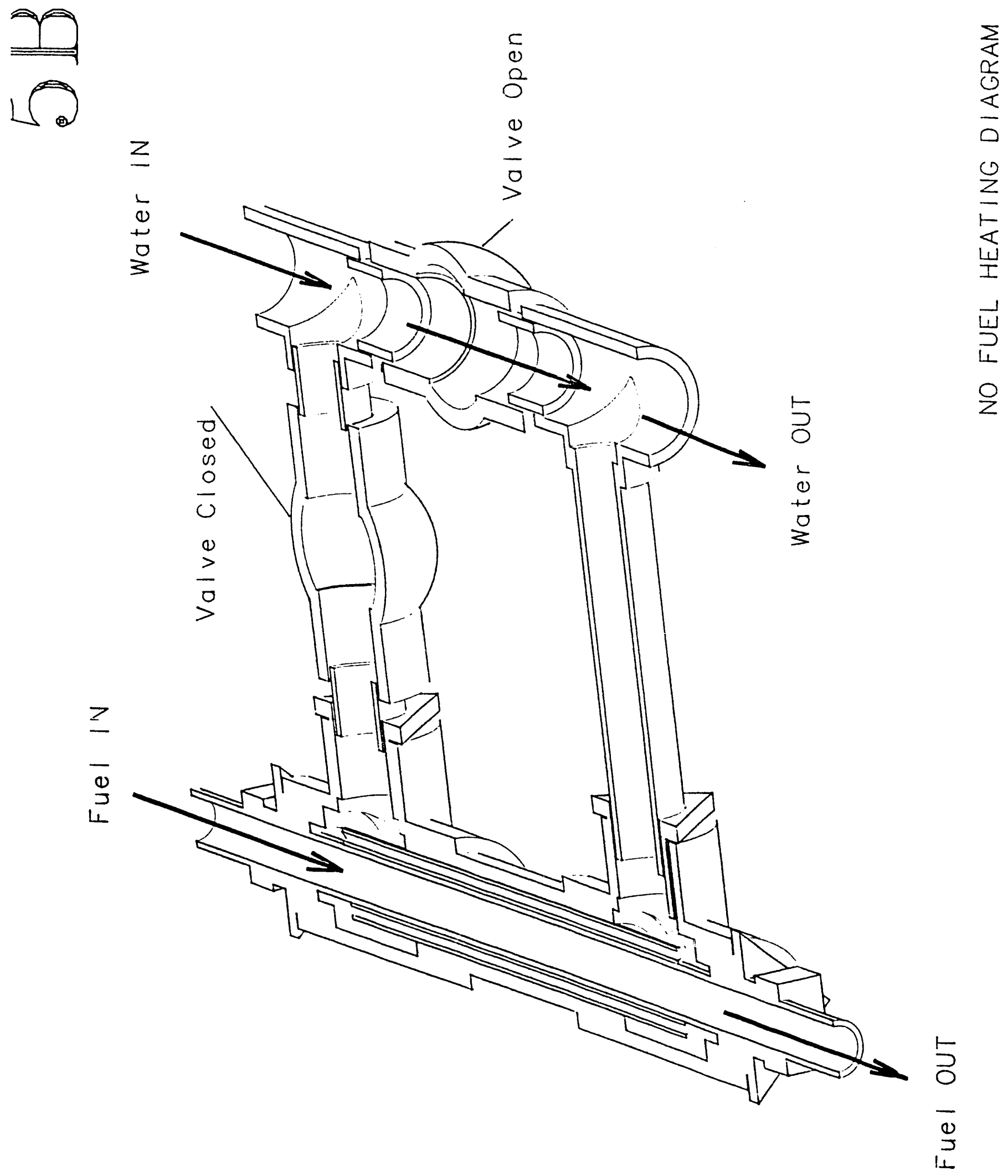


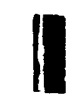

$\|$

II

I

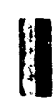

$\|$

1

II

II

II

1

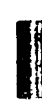

II

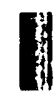

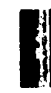

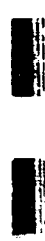

10

일

늠

(5)

응

80

ษト

$x+$

용

옹

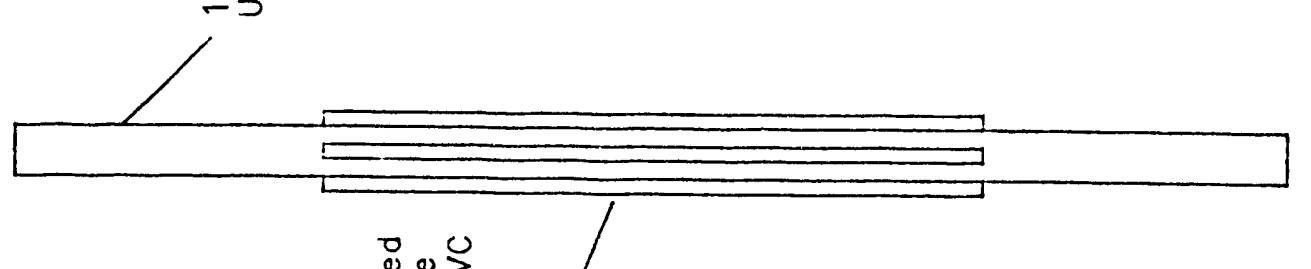

\&0

$0>0$

응.

nis:-

주융

$\overline{0} \div$

금으응

WR

ตํ.ษ ำ

중

미 $x$

ᄂ

무응

잉 生

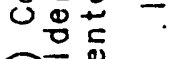

ذ穴

亏0음

낭ㄷㅇㅇ․ 

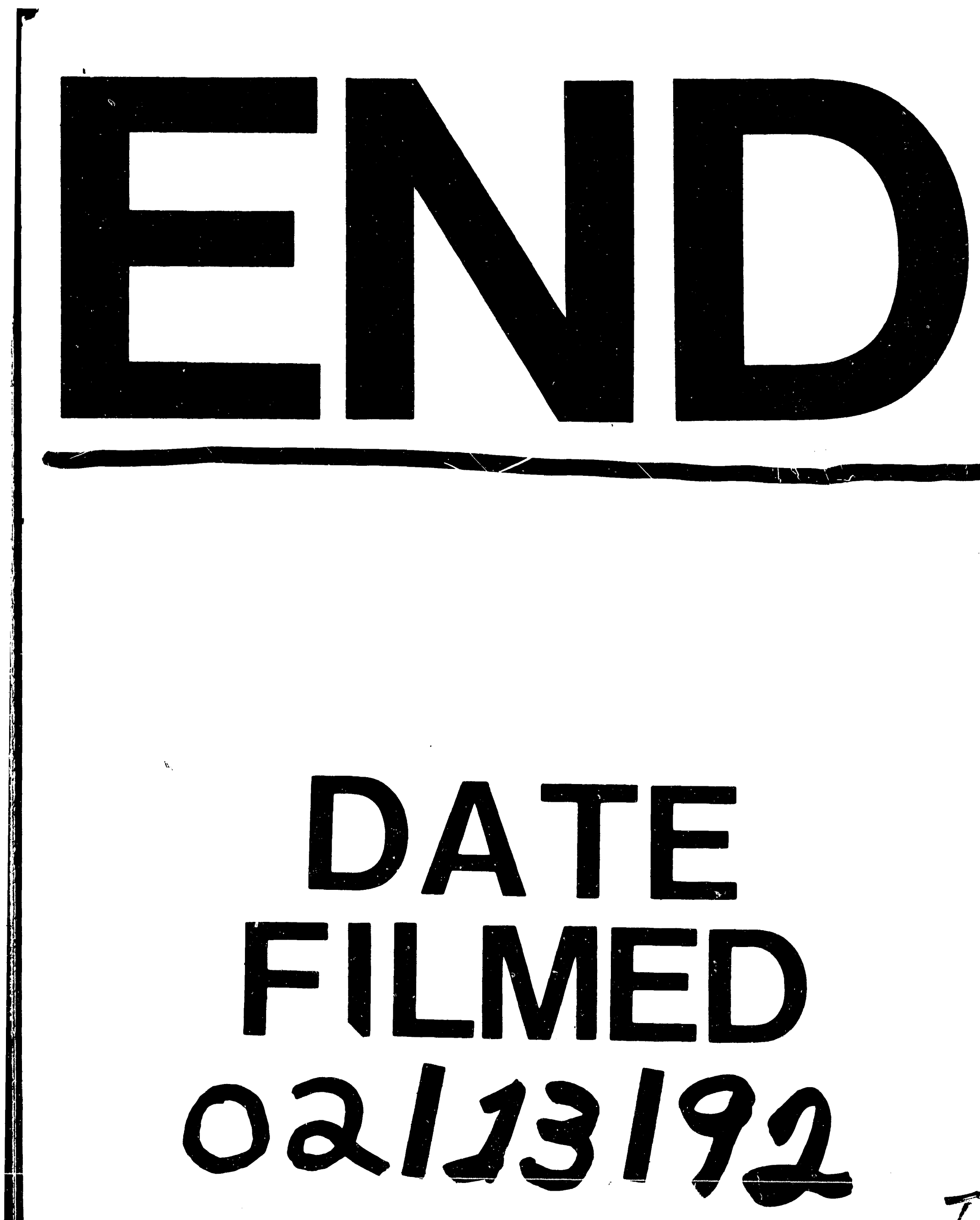

$I$ 


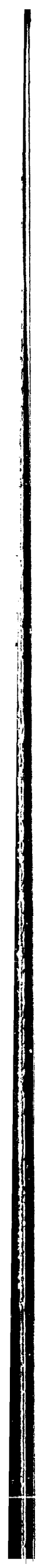

